\title{
Ocean Acoustic Waveguide Remote Sensing (OAWRS) of marine ecosystems
}

\author{
Srinivasan Jagannathan ${ }^{1}$, Ioannis Bertsatos ${ }^{1}$, Deanelle Symonds ${ }^{1}$, Tianrun Chen ${ }^{1}$, \\ Hadi Tavakoli Nia ${ }^{1}$, Ankita Deepak Jain ${ }^{1}$, Mark Andrews ${ }^{2}$, Zheng Gong ${ }^{2}$, \\ Redwood Nero ${ }^{3}$, Lena Ngor ${ }^{1}$, Mike Jech ${ }^{4}$, Olav Rune God ${ }^{5}$, Sunwoong Lee ${ }^{1}$, \\ Purnima Ratilal ${ }^{2}$, Nicholas Makris ${ }^{1, *}$ \\ ${ }^{1}$ Department of Mechanical Engineering, Massachusetts Institute of Technology, 77 Massachusetts Avenue, Cambridge, \\ Massachusetts 02139, USA \\ ${ }^{2}$ Department of Electrical and Computer Engineering, Northeastern University, 360 Huntington Avenue, Boston, \\ Massachusetts 02115, USA \\ ${ }^{3}$ Naval Research Laboratory, 4555 Overlook Avenue SW, Washington DC 20375, USA \\ ${ }^{4}$ Northeast Fisheries Science Center, 166 Water Street, Woods Hole, Massachusetts 02543, USA \\ ${ }^{5}$ Institute of Marine Research, PO Box 1870, Nordnes, 5817 Bergen, Norway
}

\begin{abstract}
Ocean Acoustic Waveguide Remote Sensing (OAWRS) has recently been shown to be capable of instantaneously imaging and continuously monitoring fish populations over continental shelf-scale areas, covering thousands of $\mathrm{km}^{2}$. We show how OAWRS can be used in a variety of oceanic ecosystems to remotely assess populations and study the behavior of fish and other marine organisms, such as Antarctic krill, to help the study of marine ecology and the ecosystem-based approach to fisheries management.
\end{abstract}

KEY WORDS: Ecosystem - Acoustic sensing $\cdot$ Instantaneous wide-area $\cdot$ Continuous monitoring Abundance $\cdot$ Behavior $\cdot$ OAWRS $\cdot$ Remote species classification

Resale or republication not permitted without written consent of the publisher

\section{INTRODUCTION}

Fish populations often comprise the largest biomass component in a productive marine ecosystem. They typically play an essential role in inter-trophic energy transport (Cury et al. 2001), and serve as a mainstay for human consumption comprising roughly $16 \%$ of the animal protein consumed by the world's population (FAO 1997). Despite their ecological importance, there is substantial evidence that fish populations are declining worldwide (Jackson et al. 2001, Myers \& Worms 2003), which has led to calls for an ecosystem approach to fisheries management (Cury et al. 2001, Browman \& Stergiou 2004, Stergiou \& Browman 2005) through ecosystem-scale sensing and monitoring of marine habitats (Godø 2009). This vision, however, is difficult to attain with conventional methods (Simmonds \& MacLennan 2005) which typically rely on in-situ measurements restricted to the immediate vicinity (tens to hundreds of meters) of slow moving research vessels and greatly undersample the ocean in time and space (Sund 1935, Balls 1948, Misund 1997, Medwin \& Clay 1998, Simmonds \& MacLennan 2005). Recently, a method known as Ocean Acoustic Waveguide Remote Sensing (OAWRS) was developed for instantaneous imaging and continuous monitoring of fish populations and marine life over continental shelf-scale areas, covering thousands of $\mathrm{km}^{2}$, at an areal rate tens of thousands to millions of times greater than that of conventional methods (Makris et al. 2006a). Continuous monitoring with OAWRS produces unaliased wide-area movies of the spatial and temporal distributions of fish populations that can reveal horizontal behavioral patterns on an ecosystem scale. This may enable better modeling and prediction of ecosystem dynamics as well as correlation with physical and biological variables including those describing oceanography, climate, food, predation and human activity, and help to realize ecosystem approaches to fisheries management. 
Ocean waveguide acoustics has been used for underwater remote sensing in all oceans for on the order of a century (Urick 1983). It takes advantage of the fact that it is always possible to form an acoustic waveguide in the ocean by trapping sound between the ocean-atmosphere and the ocean-seabed boundaries, as is described in numerous textbooks (e.g. Bergmann 1948, Officer 1958, Clay \& Medwin 1977, Urick 1983, Brekhovskikh \& Lysanov 1991, Frisk 1994, Jensen et al. 2000). In the early 19th century the principal applications were naval (Bergmann 1948, Clay \& Medwin 1977, Urick 1983). The world's navies still depend upon ocean waveguide acoustics as the primary underwater remote sensing tool for both surface and sub-surface vessels as well as in fixed installations such as the sound surveillance system (SOSUS) network (Urick 1983, Munk et al. 1995). In these applications, horizontal sensing ranges typically span distances many orders of magnitude larger than the water depth (Bergmann 1948, Ewing \& Worzel 1948, Officer 1958, Tolstoy \& Clay 1966, Clay \& Medwin 1977, Urick 1983, Brekhovskikh \& Lysanov 1991, Frisk 1994, Jensen et al. 2000). From the latter part of the 19th century until now, ocean waveguide acoustics has been used for a wide variety of oceanographic remote sensing applications, including quantification of ocean and seabed structure and passive tracking of vocalizing marine mammals (Officer 1958, Tolstoy \& Clay 1966, Clay \& Medwin 1977, Urick 1983, Brekhovskikh \& Lysanov 1991, Frisk 1994, Jensen et al. 2000, Medwin 2005).

In this paper, we first review the background and some of the recent ecological findings made with OAWRS. We describe a potential method for remote species classification, which we demonstrate with field data. We then show how OAWRS may be used in oceanic ecosystems to remotely assess populations and study the behavior of fish and other pelagic organisms, such as Antarctic krill, over broad temporal and spatial scales. A technical description of the OAWRS approach appears in Appendices A to F.

\section{BACKGROUND}

The use of acoustics to detect oceanic fish dates back to the vertical echo-sounders introduced in the 1930s (Balls 1948, 1951). During the 1940s, researchers in the University of California's Division of War Research (UCDWR) noted a mid-water layer scattering agent, which was later called 'deep scattering layer' (DSL) (Duvall \& Christensen 1946, Eyring et al. 1948, Raitt 1948). After bathypelagic fish with gas-filled swimbladders were proposed to be the cause of this DSL (Marshall 1951), the frequency response of these fish was studied to identify resonance (Hersey et al. 1962, Andreeva 1964, Andreeva \& Chindonova 1964, Marshall \& Chapman 1964, Andreeva 1965). For a good historical review of the vast literature on the ability of gas-filled fish bladders to scatter sound see Hersey \& Backus (1962) and Weston (1967). In all the above experiments, the range at which the fish were imaged was $<500 \mathrm{~m}$.

Weston \& Revie (1971) used a fixed single-beam sonar in a monostatic setting to image underwater sonar returns over long ranges $(>10 \mathrm{~km})$ in a narrow horizontal angular sector. They observed temporal variations that were believed to be consistent with fish migrations, but lacked data to confirm this. Rusby et al. (1973) generated synthetic aperture images of the continental shelf environment with a towed, single-beam sidescan sonar. Each synthetic aperture image required hours of surveying, which led to high spatiotemporal undersampling and aliasing. They described features as possible fish groups 'only when the shape of the groups remain[ed] sufficiently distinctive from run to run,' which would bias the analysis towards highly static population distributions. They then guided a fishing vessel to the location of such a feature, where the vessel made a large fish catch. In these and other earlier long range experiments (Nero \& Huster 1996, Farmer et al. 1999), independent confirmation of fish was not available by simultaneous measurements.

Makris et al. $(2006,2009)$ used a horizontal array that formed simultaneous beams over a $360^{\circ}$ horizontal azimuth, enabling them to conduct OAWRS surveys of marine life instantaneously over wide areas, tens of thousands of $\mathrm{km}^{2}$. With regular and rapid temporal image updates, they were able to work in a true Eulerian reference frame and map fish distributions without aliasing in space or time. They established longrange ocean acoustics as a method for detecting, imaging, and estimating fish populations (Appendix B) by coregistration with large numbers of simultaneous OAWRS, conventional fish-finding sonar (CFFS) and trawl samples, where the latter provided direct species identification. Large numbers of simultaneous measurements are necessary for confirmation because fish are ubiquitous in continental shelf environments and can easily be found accidentally in a region causing strong acoustic returns. Non-simultaneous correlations can then easily be spurious, as can correlations at only a single or very small number of spatial locations. This lesson was learned with geologic features of the subbottom, which are also ubiquitous in many continental shelf environments, and often have spurious spatial correlation with acoustic returns caused by other mechanisms (Ratilal et al. 2005).

In earlier work at very short ranges on the order of the water depth, $\sim 300 \mathrm{~m}$, and so with conventional 
direct-path rather than waveguide propagation and sensing, Isaacs \& Schwartzlose (1965) used a U.S. Navy mine hunting sonar operating on the southern California continental shelf to detect strong scatterers which they confirmed to be fish with local trawls.

\section{INVESTIGATING FISH SHOALING BEHAVIOR OVER ECOSYSTEM SCALES}

The OAWRS approach for studying marine life was first demonstrated in 2003 off the US Continental Shelf south of Long Island, NY, i.e. the Mid-Atlantic Bight. With a single transmission of a $1 \mathrm{~s}$ duration linear frequency modulated (LFM) waveform, OAWRS surveyed an area as large as the state of Connecticut or New Jersey (Fig. 1). The imaging is effectively instantaneous because the entire region is surveyed in less time than it takes a marine organism to traverse a single OAWRS resolution cell (Makris et al. 2006b). The OAWRS approach was used again with the National Marine Fisheries Service (NMFS) annual herring survey of the Gulf of Maine and Georges Bank to study herring group behavior associated with spawning in September-October 2006 (Makris et al. 2009a). In both the OAWRS experiments, a vertical source array transmitted sound in the frequency range of 390 to $1400 \mathrm{~Hz}$, i.e. near swimbladder resonance for many fish species in the survey regions. Echoes scattered from fish were received by a towed horizontal receiv-

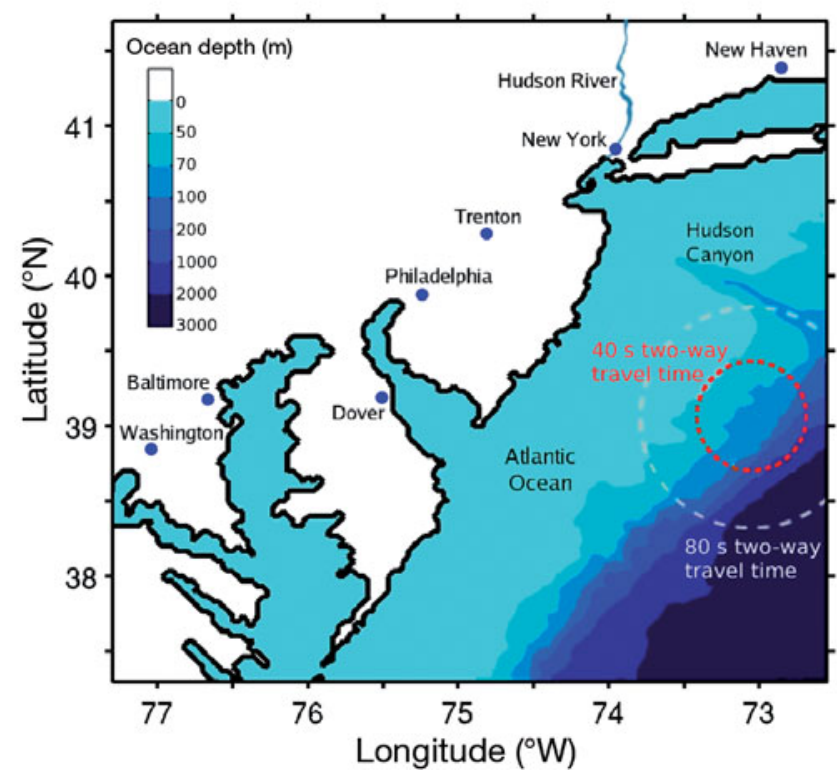

Fig. 1. Areal coverage of a single Ocean Acoustic Wakeguide Remote Sensing (OAWRS) transmission during the 2003 survey on the US east coast continental shelf. An area of $60 \mathrm{~km}$ diameter was surveyed every $40 \mathrm{~s}$ (red circle), or $120 \mathrm{~km}$ every $80 \mathrm{~s}$ (white circle), depending on ping repetition rate and recording time

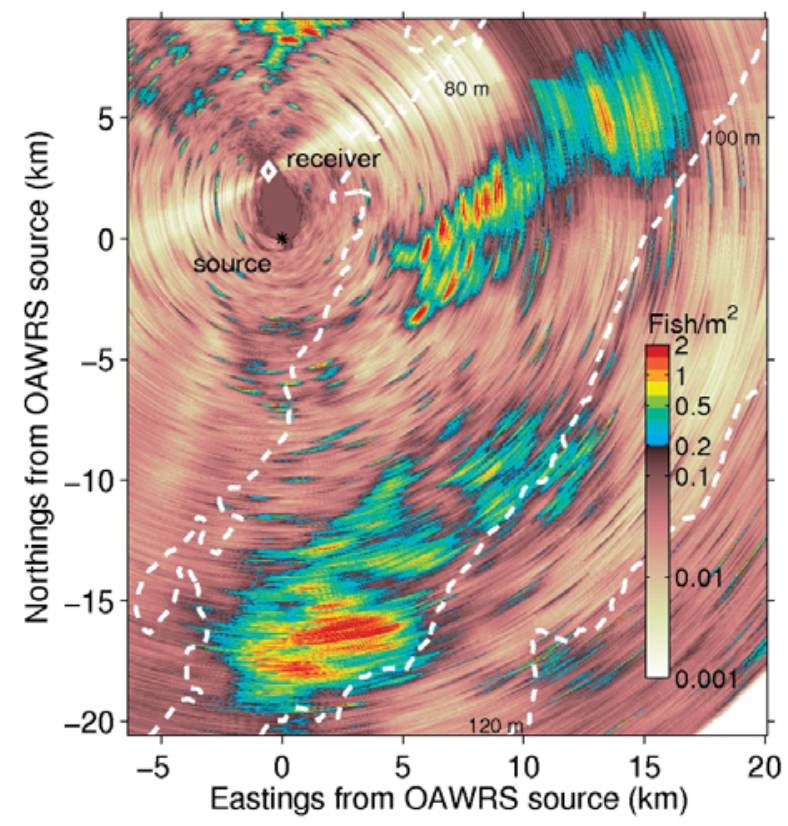

Fig. 2. Instantaneous OAWRS image showing fish shoals near the continental shelf edge $100 \mathrm{~km}$ south of Long Island, New York (May 15, 2003, 10:36 Eastern Daylight Time [EDT]). Dashed white lines mark depth contours. Receiver array resolution decreases as viewing directions go from normal (broadside) to parallel (endfire) to the array axis, leading to blurring of the eastern portion of the northeastern shoal. Population density estimation employs waveguide propagation and scattering models, correction for OAWRS areal resolution, and calibration with local conventional fish-finding sonar (CFFS) measurements as described in Appendices A to F

ing array. Instantaneous snapshots of the ocean environment over thousands of $\mathrm{km}^{2}$ (Fig. 2) were then formed by charting acoustic returns in horizontal range and bearing by temporal matched filtering and beamforming.

With the 'first look' of OAWRS in the Mid-Atlantic Bight (Fig. 1) it was possible to make a number of fundamental scientific discoveries about the (1) instantaneous horizontal structural characteristics, (2) temporal evolution, and (3) propagation of information within very large fish shoals (Makris et al. 2006a). These include the findings that: the instantaneous spatial distribution of fish observed follows a fractal or power law process, so that structural similarity exists at all scales from metres to tens of $\mathrm{km}$ (previously evidence for structural similarity existed only for small scales $<100$ m; Freon \& Misund 1999); large shoals (Fig. 2) are far more horizontally contiguous in 2D than was previously believed based on 1D line transect methods which sometimes inaccurately portray them as disjoint clusters (Pitcher \& Parrish 1993, Freon \& Misund 1999); the temporal autocorrelation scale of population change within a very large shoal is extremely short, on 


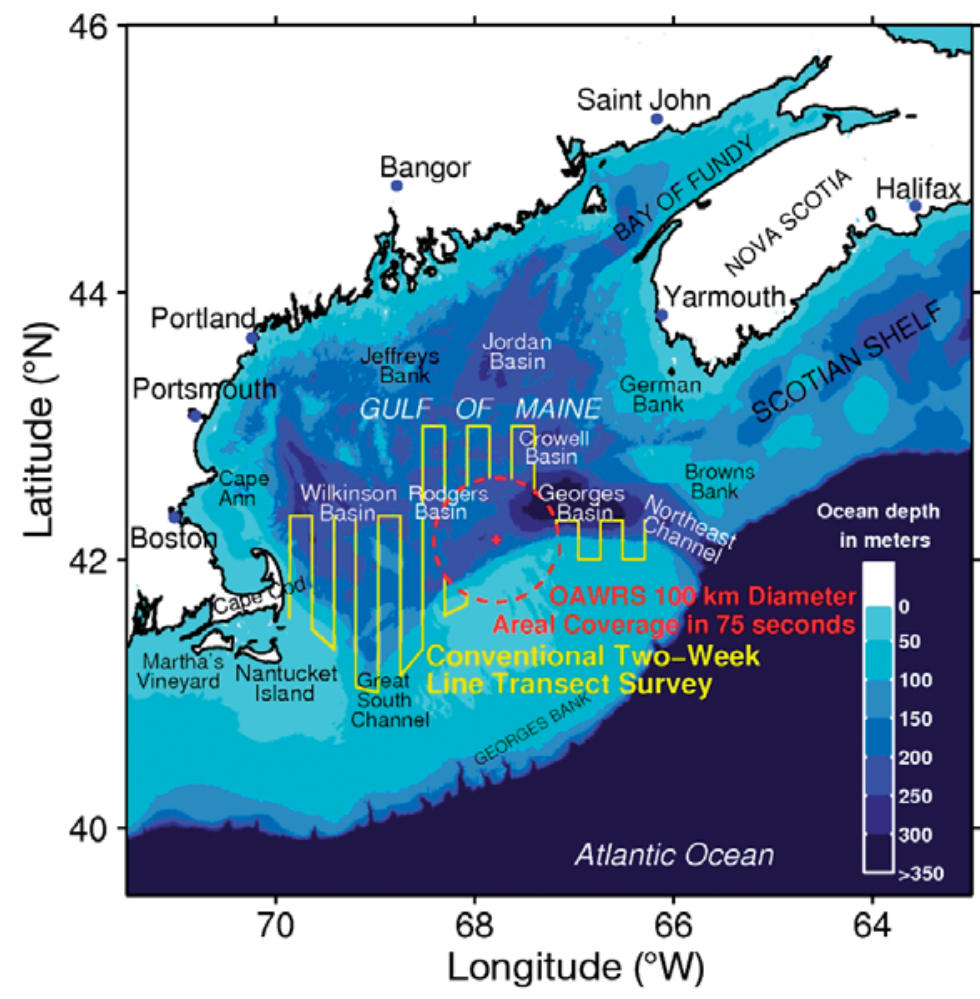

Fig. 3. Areal coverage of a single OAWRS transmission in the Gulf of Maine, 2006). A region of $100 \mathrm{~km}$ diameter (red circle) is surveyed every 75 s. Line transects of National Marine Fisheries Service (NMFS) $2 \mathrm{wk}$ survey are shown in yellow

the order of minutes, which is why fish shoals can suddenly disappear from conventional survey vessels; temporal fluctuations in shoal population also follow a power-law process, making the shoals far more predictable; and fish density waves regularly propagate information over $\mathrm{km}$ scales, 3 orders of magnitude larger than previously observed (Shaw 1970, Radakov 1973), at speeds an order of magnitude faster than fish can swim, which apparently help large shoals remain cohesive. These observations were made from distances $>10 \mathrm{~km}$ from the shoals with sound at least 3 orders of magnitude less intense than CFFS due to the efficiency of ocean acoustic waveguide propagation.

General predictions about animal group behavior believed to apply in nature irrespective of species (Vicsek et al. 1995, Toner \& Tu 1998, Reebs 2000, Couzin et al. 2005, Buhl et al. 2006) were confirmed by monitoring the Georges Bank marine ecosystem (Fig. 3) with OAWRS in the fall of 2006. By quantifying the formation process of vast oceanic herring shoals during spawning, it was shown that (1) a rapid transition from disordered to highly synchronized behavior occurs as fish population density reaches a critical value; (2) organized group migration occurs after this transition; and (3) small sets of leaders significantly influence the actions of much larger groups (Makris et al. 2009a).
The spawning process was found to follow a regular diurnal pattern in space and time which proved to be difficult to detect without continuous wide-area sensing abilities (Fig. 3). First, pre-existing populations of diffusely scattered herring reached a critical density at one or more discrete locations near the northern flank of Georges Bank just before sunset, apparently in response to diminishing light level. The emergence of leading clusters then triggered a shoal-forming convergence wave (Fig. 4) that propagated tens of $\mathrm{km}$ in tens of min, i.e. at speeds an order of magnitude greater than herring can swim (Huse \& Ona 1996, Fig. 3 of Makris et al. 2009a). Subsequent migrations were observed towards southern spawning grounds on Georges Bank, immediately after shoals formed. The evidence suggests the primary biological function of the shoals is a prelude to synchronized spawning and the shoals form in deeper water with migrations under cover of darkness to avoid predators (Makris et al. 2009a).

As Vicsek et al. (1995) theoretically predicted, and Buhl et al. (2006) showed with laboratory experiments, if an individual assumes the mean speed and direction of those in its sphere of perception, then a rapid transition from disordered to highly synchronized behavior occurs when a critical population density is attained. This may be understood by noting that as the radii of perception begin to overlap with increasing population density, chain reactions become possible. Laboratory experiments (Reebs 2000) and simulations (Couzin et al. 2005) showed that a small number of individuals can significantly influence decision making in large groups.

\section{REMOTE SENSING OF SWIMBLADDER PROPERTIES}

For fixed fish length and water depth, acoustic scattering at, or near, swimbladder resonance is a strong function of swimbladder volume (Fig. 5, Supplement 1 at www.int-res.com/articles/suppl/m395p137_ app.pdf). The acoustic scattering can vary significantly across species and so may be helpful in species classification, as has been discussed for salmon (Nero \& Huster 1996), blue whiting (Love 1993), Pacific hake (Nero et al. 1998), and Atlantic herring (Nero et al. 2004). Swimbladder volume can also be used to estimate neutral buoyancy depth, where a fish's weight is balanced by its buoyancy (Nero et al. 2004). At any given depth, neutral buoyancy requires the swimbladder to occupy $\sim 5 \%$ of the total fish volume (Jones \& 
Fig. 4. Example of regular diurnal pattern of large pre-spawning shoals forming near sunset (18:08 h EDT) on Oct 03, 2006. Top panel: $1 \mathrm{hr} 45 \mathrm{~min}$ before sunset-no shoal present. Bottom panel: $10 \mathrm{~min}$ after sunsetlarge shoal present. White dashed lines mark depth contours. Population density estimation employs waveguide propagation and scattering models, correction for OAWRS areal resolution, and calibration with local CFFS measurements as described in Appendices A to F. The positive vertical axis points $16^{\circ}$ counter-clockwise of true north

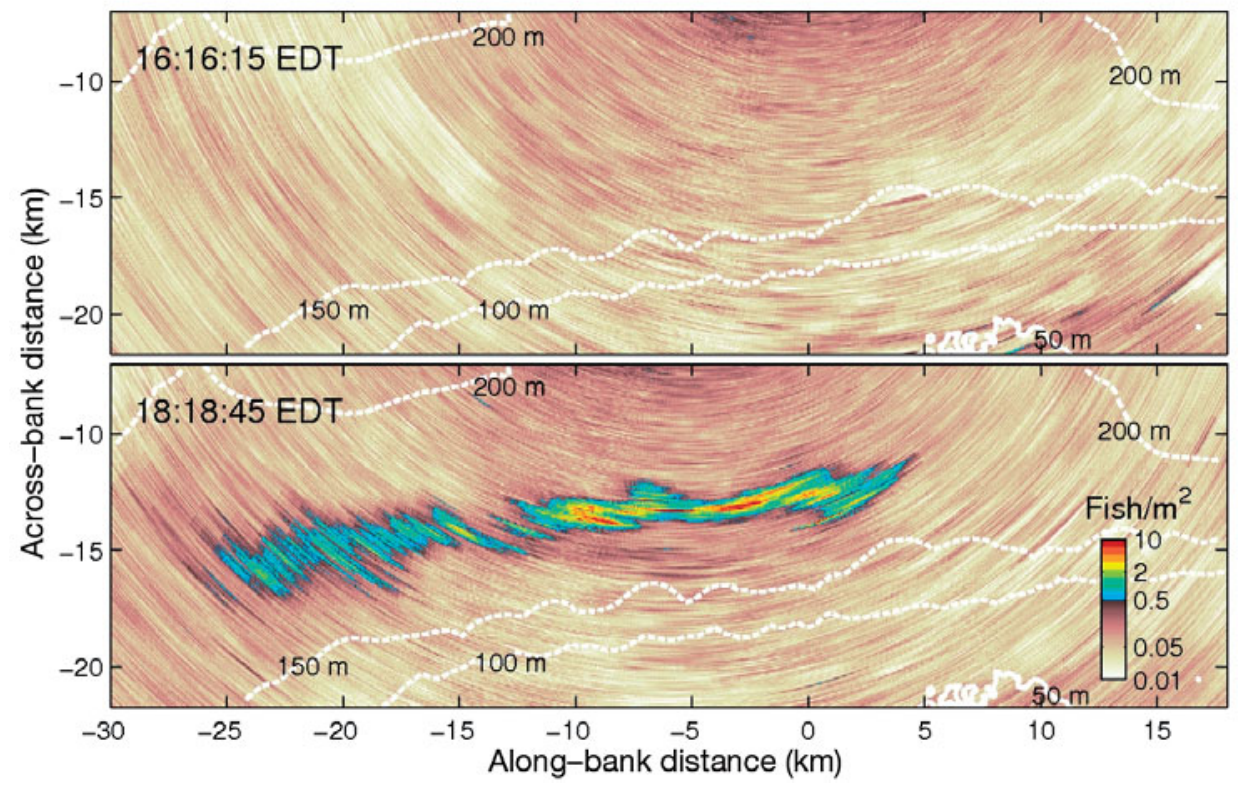

Marshall 1953), where more air is required to maintain this ratio as depth increases due to the compressive effects of increasing pressure.

We used OAWRS to determine swimbladder volume and help classify the species of shoaling fish observed during the 2003 OAWRS experiment (Fig. 2) (Makris et al. 2006a). The mean scattering cross-section of a shoaling fish determined with OAWRS 2003 data and local CFFS constraints is shown in Fig. 5 in terms of target strength (TS) following the approach given in Appendix E for 3 frequencies 415, 925, and $1325 \mathrm{~Hz}$ corresponding to the center frequencies of the 390 to 440, 875 to 975 and 1250 to $1400 \mathrm{~Hz}$ LFM waveforms used in OAWRS 2003 (Makris 2003, Makris et al. 2006a). The least squares fit between the empirically determined OAWRS TSs and those determined from a standard fish scattering model (Love model, Supplement 1), with CFFS-measured constraints on fish habitation depth and length, leads to a neutral buoyancy depth of $78 \mathrm{~m}$ with a resonance peak at $\sim 700 \mathrm{~Hz}$ (black solid line in Fig. 5), consistent with the CFFS-measured shoal layer at 70 to $90 \mathrm{~m}$ depth. While buoyancy depth need not correspond to habitation depth, the correspondence is advantageous because it enables fish to expend minimal energy to maintain a depth.

While the ability to regulate neutral buoyancy over a wide range of depths is usually associated with physoclist fish (closed swimbladders), physostome fish (swimbladder with open duct to the intestine) also have this ability (Brawn 1962, Sundnes \& Sand 1975). Physoclists are known to slowly regulate the swimbladder volume through the blood stream (Jones \& Marshall 1953) and
Fig. 5. Target strength (TS) data for 3 frequencies (circles \pm SD; independent samples; $415 \mathrm{~Hz}: \mathrm{n}=181, \mathrm{SD}=$ $0.7 \mathrm{~dB} ; 925 \mathrm{~Hz}: \mathrm{n}=46, \mathrm{SD}=5.5 \mathrm{~dB} ; 1325 \mathrm{~Hz}: \mathrm{n}=46, \mathrm{SD}$ $=5 \mathrm{~dB}_{\text {; }}$ see Appendix E) corresponding to the mean scattering cross section of a shoaling fish species in the OAWRS 2003 experiment constrained by local CFFS. TS frequency curves for 5 different neutral buoyancy depths are computed with Love's model (US Navy standard for low frequency fish scattering; Supplement 1 at www.int-res.com/articles/suppl/m395p137_app.pdf) by depth-averaging the expected scattering cross section of an individual fish over the layer observed by CFFS for the Gaussian length distribution (SD 15\% of the $28.6 \mathrm{~cm}$ mean) determined by CFFS. The least-squares best-fit buoyancy depth between measured data to Love-model TS is given by the black solid line. If the shoaling fish observed in the 70 to $90 \mathrm{~m}$ layer were neutrally buoyant closer to the surface (grey line), they would scatter far too weakly below $1.4 \mathrm{kHz}$ to be consistent with the measured OAWRS and CFFS data

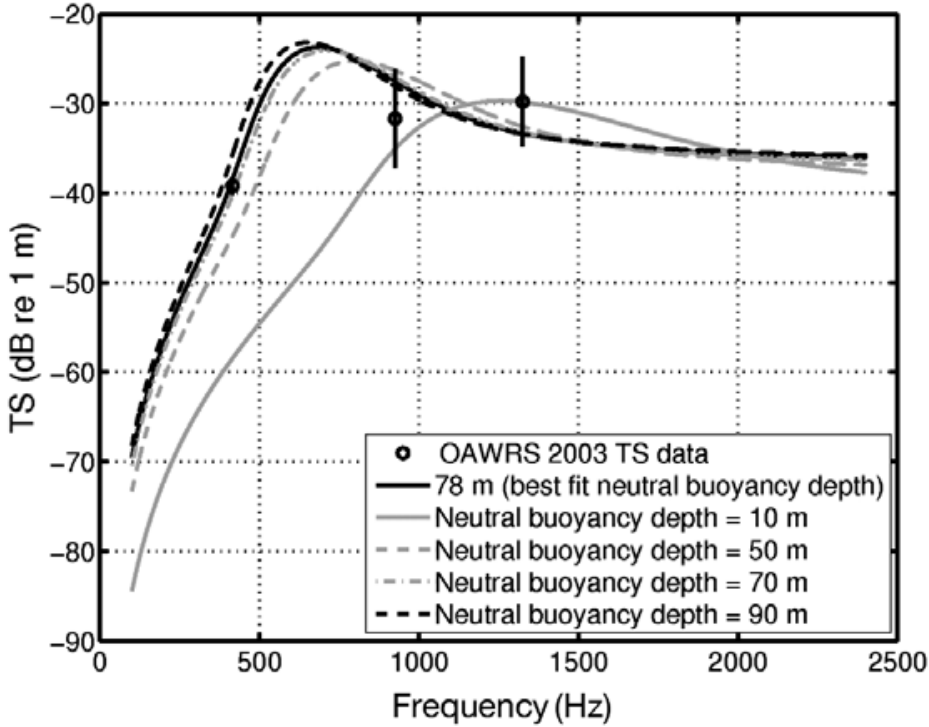


so can achieve neutral buoyancy at any depth, given enough time to adjust (Blaxter \& Tytler 1978, Harden Jones \& Scholes 1985). Physostomes, on the other hand, can fill their swimbladders by gulping air at the surface (Blaxter \& Batty 1984). If this was the only mechanism for them to increase the volume of gas in their swimbladder, then their maximum neutral buoyancy depth would be limited by the maximum volume they could gulp at the surface (Thorne \& Thomas 1990, our Fig. S1). Thorne \& Thomas (1990) measured neutral buoyancy depths of up to $\sim 60 \mathrm{~m}$ for herring, a physostome, and suggest additional gas production mechanisms, such as from bacteria in the digestive tract (Brawn 1962). In 1 of 6 experiments, Brawn (1962) found swimbladder volume build-up by non-gulping mechanisms within less than $24 \mathrm{hr}$ in herring that were heavily fed with copepods containing bacteria. Neutral buoyancy depths of 40 to $50 \mathrm{~m}$ have been determined from near resonance scattering data (Nero et al. 2004). Char, another physostome, have also been found to build up gas in their swimbladder even when denied access to the surface (Sundnes \& Sand 1975). The fish imaged by OAWRS were consistently observed in a 70 to $90 \mathrm{~m}$ layer near the seafloor for $>12 \mathrm{~h}$ by CFFS. The long periods that the fish spent at these depths could be sufficient for both physoclists and physostomes to build up gas in their swimbladder.

From trawl surveys of the New Jersey continental shelf taken 1 mo prior to the 2003 experiment, we list the most probable species that could have comprised the shoals imaged by OAWRS based on frequency of catch: Atlantic herring, scup, hake, black sea bass and alewife (NEFSC Resource Survey Report 2003, Makris et al. 2006b). While dogfish and mackerel are also found in the area (NEFSC Resource Survey Report 2003), their scattering responses are expected to be much lower than those of the mentioned fish as dogfish and mackerel lack gas-filled bladders. Of the species typically found in the region, only Atlantic herring and alewife are physostomes, while scup, hake and black sea bass are physoclists. Since Atlantic herring is the most common species sampled in the region (NEFSC Resource Survey Report 2003), and the only one known to form such large, extended shoals, they are most likely the major constituent of the large shoals imaged by OAWRS in 2003 and the dominant cause of scattering measured by both OAWRS and CFFS. The fit between measured TS data and the Love fish scattering model constrains the suspected herring to neutral buoyancy at $78 \mathrm{~m}$ depth, which suggests that they should have a mechanism for building up gas in their swimbladder, or they have damping mechanisms which lower and spread the resonance and have shallower neutral buoyancy depth. It is unlikely that another, less abundant species could have dominated the scattering measured by OAWRS and CFFS, since this would require 'contaminants' with unrealisti- cally large target strengths to follow the exact spatial distributions of the shoals observed at both OAWRS and CFFS frequencies. Such contamination is inconsistent with trawl data (NEFSC Resource Survey Report 2003), the observed preference of fish to shoal among similarsized individuals (Pitcher \& Parrish 1993), and stationarity of CFFS and OAWRS scattering measurements (Appendix E), which show fish of similar length and target strength. The target strengths of shoaling fish in the OAWRS 2003 experiment are consistent with those measured for herring in the 2006 experiment where trawl samples enabled direct species identification (Makris et al. 2009a).

\section{POTENTIAL ECOSYSTEM EXPLORATION}

OAWRS can be used to remotely sense a variety of fish species and other marine organisms, such as Antarctic krill, over broad temporal and spatial scales in ocean ecosystems from knowledge of (1) the expected scattering cross section of an individual (Supplement 1), (2) typical population densities, (3) acoustic propagation (Appendix D) and (4) seafloor scattering in each environment (Appendix F). Since the emphasis of the main text is on marine biology and ecology, we discuss physical acoustics issues in Appendices A to F and Supplement 1.

A wide range of transmission frequencies may be used for OAWRS, ranging from very low frequencies of several $\mathrm{Hz}$ to high frequencies of tens of $\mathrm{kHz}$. Longrange sound propagation in the ocean is less attenuated at lower frequencies and is less sensitive to oceanographic fluctuations. Reverberation from the seafloor tends to be weaker at lower frequencies.

When designing an OAWRS system we need to consider operating at frequencies where fish scattering responses are high. Optimal OAWRS frequencies should be low enough for scattering from any fish to be effectively omni-directional, to make OAWRS insensitive to variations in fish orientation, which is typically not the case in CFFS. Frequency should also be low enough for the received acoustic field scattered from any given fish to be expressible as the product of the 3 factors 'transmission to the given fish', 'scattering from the fish', and 'transmission from the fish' (Appendix C). At CFFS wavelengths, this factorization is typically not possible because propagation and scattering effects are convolved together in an ocean waveguide (Ratilal et al. 2002). Frequencies should be chosen so that acoustic attenuation from propagation through the fish is negligible even over long ranges. If the frequency is too low, on the other hand, the waveguide may no longer support modal propagation (Appendix A), and so remote sensing may become inefficient. 


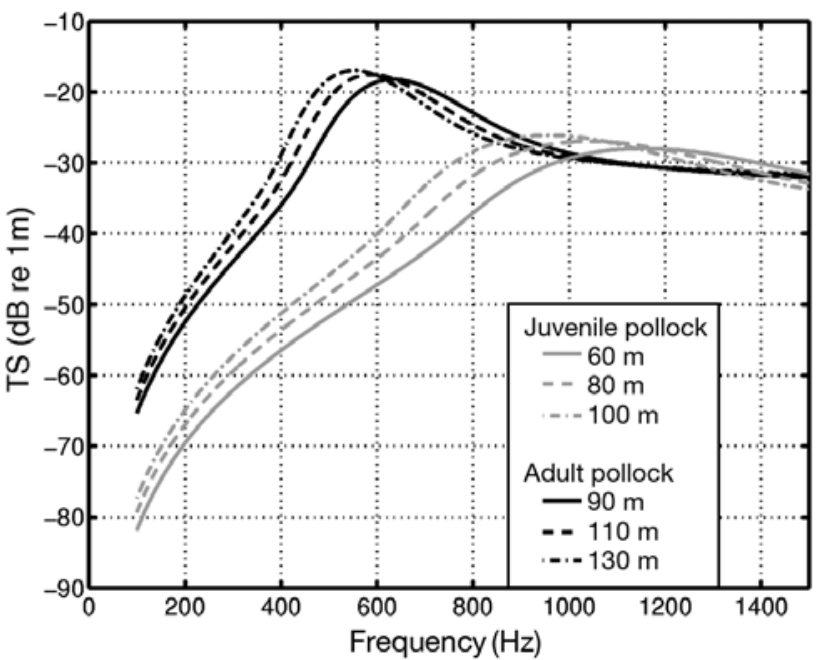

Fig. 6. Theragra chalcogramma. Modeled target strength (TS) for juvenile and adult pollock in the Gulf of Alaska for varying neutral buoyancy depths ( 60 to $130 \mathrm{~m}$ ). The expected TS at a given frequency is found by averaging the scattering cross section over the range of depths and mean body lengths typically associated with these fish (Table 1). The body lengths of adults and juveniles are assumed to have a Gaussian distribution, and a SD of $10 \%$ of the respective means. Details of the modeling appear in Supplement 1

\section{Alaskan pollock Theragra chalcogramma}

Alaskan pollock are a semi-pelagic schooling fish widely distributed in the North Pacific Ocean. They comprise the largest percentage of biomass of any species in the Bering Sea ${ }^{\mathbf{1}}$ and are an important predator that feed on smaller fish and also cannibalize their juveniles (Dwyer et al. 1987). So, in the Gulf of Alaska, adults are more often found near the bottom (110 to $130 \mathrm{~m}$ ) while juveniles prefer to stay separate above (70 to $100 \mathrm{~m}$ ) (Wilson et al. 2003). We use the parameters summarized in Table 1 to describe the pollock, a physoclist species assumed to be neutrally buoyant at the depths they occupy.

When operating at the resonance peak near $600 \mathrm{~Hz}$ (Fig. 6), OAWRS should be able to detect adult pollock schools of a density of 5 fish $\mathrm{m}^{-2}$ with a signal to noise ratio (SNR) (Appendix F) of 30 to $40 \mathrm{~dB}$ (Fig. 7). OAWRS detections of pollock should then span a dynamic range of 30 to $40 \mathrm{~dB}$ in population density, from maximum values of 5 fish $\mathrm{m}^{-2}$ (Table 1) to minimum detectable values of $5 \times 10^{-4} \mathrm{fish} \mathrm{m}^{-2}$. Single pollock should then be observable to a range of about $3 \mathrm{~km}$ with the OAWRS 2003 system. Above resonance, densities of at least $10^{-2}$ fish $\mathrm{m}^{-2}$ are required, but this is still much lower than the typical shoaling densities of

${ }^{1}$ Alaska Fisheries Science Center NOAA Fisheries. Accessed 26 Feb 2009. www.afsc.noaa.gov/species/pollock.php

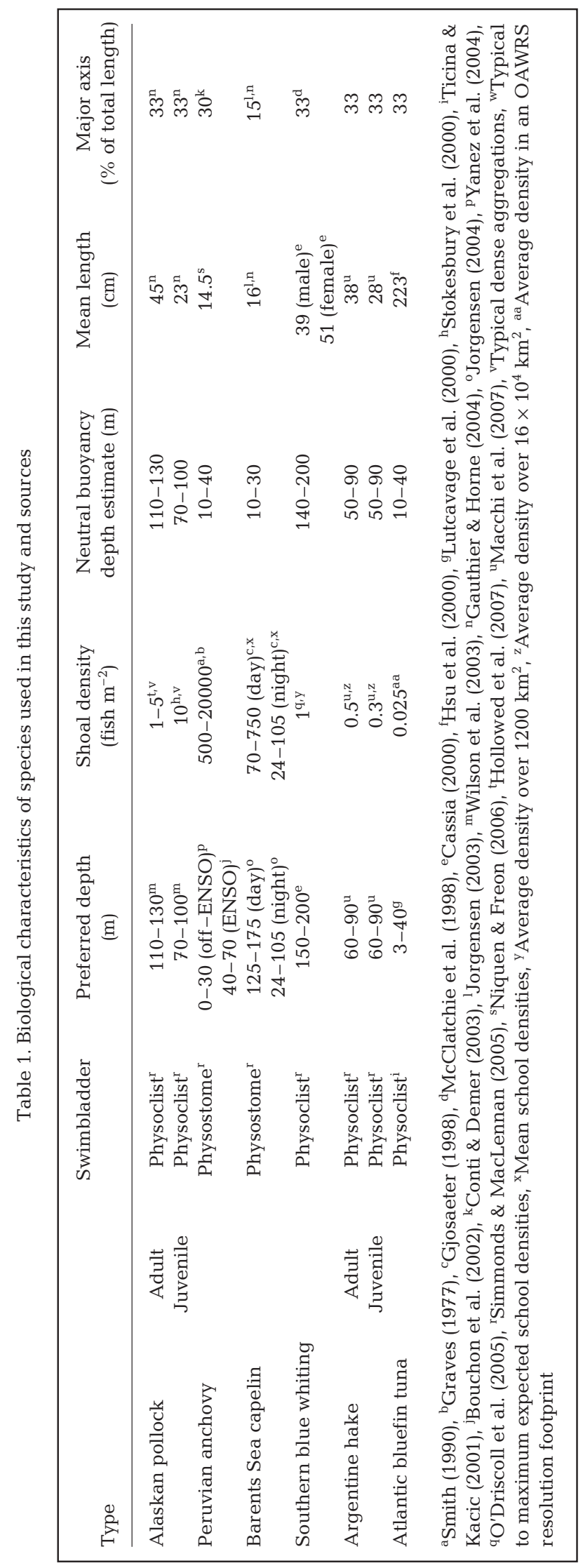


pollock (Table 1). Even at these higher frequencies, detections above seafloor scattering should span a dynamic range of at least 2 to 3 orders of magnitude, or 20 to $30 \mathrm{~dB}$, in population density.

Schools of juvenile pollock should be detectable by OAWRS at resonance, which is relatively broad, over a dynamic range of at least $30 \mathrm{~dB}$ (Fig. 7) in population density, from maximum expected values of $10 \mathrm{fish} \mathrm{m}^{-2}$ (Table 1) to minimum detectable values of 0.01 fish $\mathrm{m}^{-2}$.

\section{Peruvian anchovy Engraulis ringens}

Peruvian anchovy play an essential role in the Humbolt Current upwelling ecosystem as an energy intermediary between phytoplankton and large predatory fish, such as hake and horse mackerel. The diets and livelihood of seabirds, marine mammals, livestock and humans, are also directly tied to anchovy. For details on the Peruvian anchovy fishery see Niquen \& Freon (2006).

Anchovy have a fairly low tolerance to temperature variations, preferring to stay in the 13 to $23^{\circ} \mathrm{C}$ range (Gutierrez et al. 2007). Therefore, their geographic and depth distributions are highly susceptible to climate change, such as the El Nino Southern Oscillation (ENSO). The deepening of the thermocline and the migration of food sources during ENSO periods cause anchovies to descend to greater depths (Niquen \& Diaz 2002). The average depth range of the Peruvian stock is

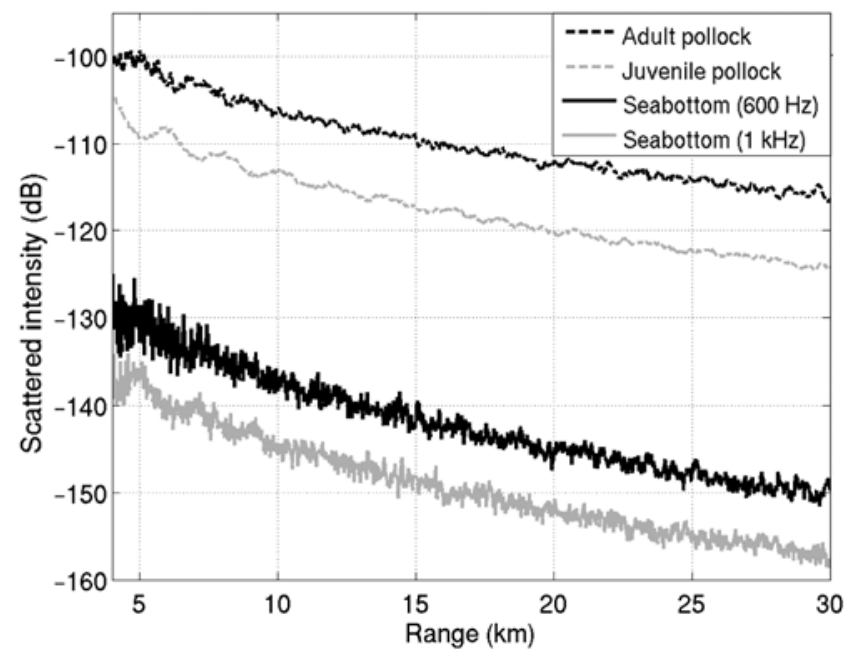

Fig. 7. Theragra chalcogramma. Scattered intensity from adult and juvenile pollock and the seabottom modeled at $600 \mathrm{~Hz}$ (black lines) and $1 \mathrm{kHz}$ (grey lines). Pollock are assumed to be uniformly distributed in depth layers (adult: 110 to $130 \mathrm{~m}$; juvenile: 70 to $100 \mathrm{~m}$ ) and at densities of 5 adult and 10 juvenile ind. $\mathrm{m}^{-2}$ (Table 1 ). A description of the modeling appears in Appendices C, D and F

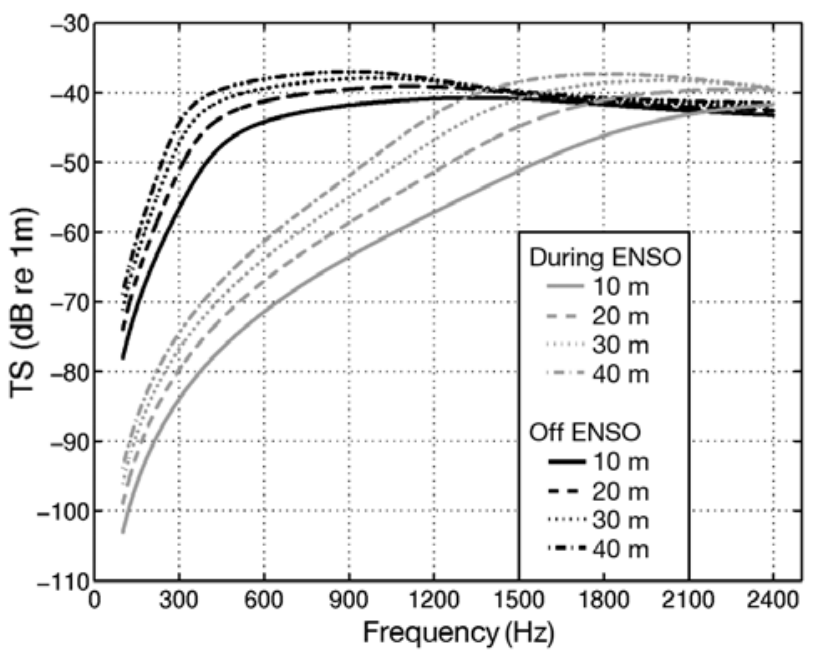

Fig. 8. Engraulis ringens. Modeled target strength for anchovy off the Peruvian coast for different neutral buoyancy depths. Same procedure as that employed in Fig. 6. Anchovy in 0 to $30 \mathrm{~m}$ during off-ENSO: black lines. Anchovy in 40 to $70 \mathrm{~m}$ during ENSO: grey lines. The variation in neutral buoyancy corresponds to minor axis at the surface expanding by a factor of $\sim 1.4$ to 2.2 (Fig. S1 in Supplement 1)

0 to $30 \mathrm{~m}$ (Bouchon et al. 2002, Yanez et al. 2004) except during ENSO, when they are found at a range of 40 to $70 \mathrm{~m}$ (Blanco et al. 2002).

Anchovy have an average length of 14 to $16 \mathrm{~cm}$ (Bouchon et al. 2002) (maximum length $\sim 20 \mathrm{~cm}$; Gutierrez et al. 2007). Catches in 2005 showed an average length of $14.5 \mathrm{~cm}$ (Niquen \& Freon 2006). Anchovy are known to form huge schools (Tran 2003) and packing densities of 115 (Graves 1977) to 1312 (Smith 1970) fish $\mathrm{m}^{-3}$ have been reported for Engraulis mordox.

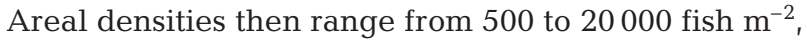
given typical vertical school extents of 4 (Holliday \& Larson 1979) to $15 \mathrm{~m}$ (Huntley \& Zhou 2004). E. ringens, E. japonicus and E. encrasocolus display similar schooling characteristics as E. mordox (Huntley \& Zhou 2004).

During both ENSO and off-ENSO periods, anchovy should be detectable by OAWRS over a dynamic range of $45 \mathrm{~dB}$ in population density, from 20000 to minimum detectable values of 0.6 fish $\mathrm{m}^{-2}$, which is much lower than typical schooling densities (Table 1).

When operating at $1.2 \mathrm{kHz}$, where uncertainties in target strengths are lowest (Fig. 8), OAWRS should be able to detect anchovy schools with an areal density of 20000 fish $\mathrm{m}^{-2}$ (15 $\mathrm{m}$ thick layer of fish (Huntley \& Zhou 2004); 1 body-length inter-fish spacing (Pitcher \& Partridge 1979); Table 1) with an SNR of 45 dB (Fig. 9) during off-ENSO periods. During ENSO, OAWRS should be able to detect anchovy schools of 20000 fish $\mathrm{m}^{-2}$ with an SNR of $45 \mathrm{~dB}$ (Fig. 9) when operating at $2.4 \mathrm{kHz}$, above resonance (Fig. 8). 


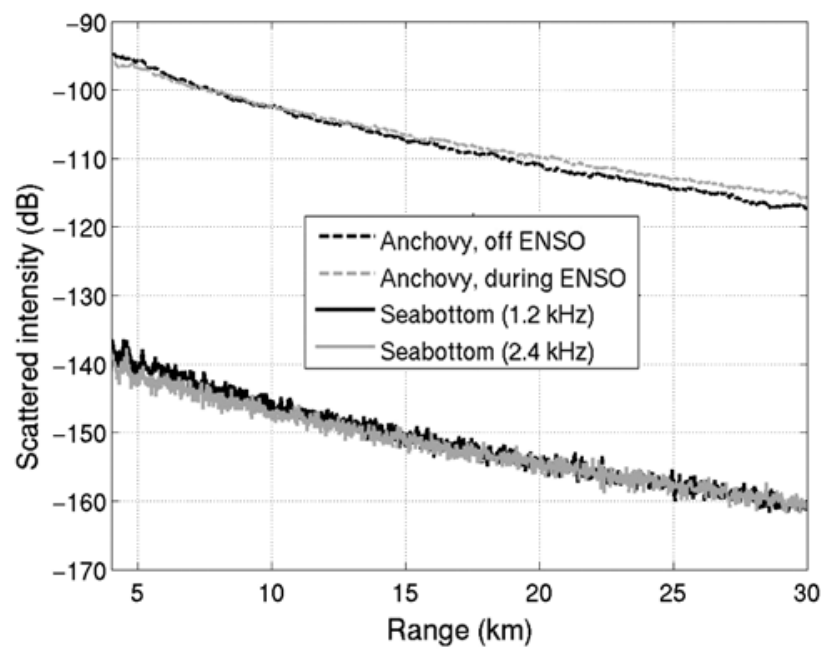

Fig. 9. Scattered intensity from anchovy during off-ENSO (black lines) and ENSO periods (grey lines) and sea bottom modeled at $1.2 \mathrm{kHz}$ and $2.4 \mathrm{kHz}$ respectively, and for a maximum density of 20000 fish $\mathrm{m}^{-2}$. The schools are assumed to be distributed with uniform probability within the top $30 \mathrm{~m}$ (offENSO), and within 40 to $70 \mathrm{~m}$ (ENSO) depth

\section{Barents Sea capelin Mallotus villosus}

The Barents Sea holds the largest capelin population in the world and this species is the largest pelagic fish component of the region, with a biomass reaching 6 to $8 \times 10^{6}$ t (Gjosaeter 1998). Capelin play a key role in energy conversion from zooplankton to higher trophic predators, such as haddock, harp seal, Northeast Arctic cod, whales, and sea birds (Gjosaeter 1998), and is also important to human and livestock consumption (Froese \& Pauly 2009). Capelin undergo drastic diel vertical migration patterns, occupying depths of 30 to $60 \mathrm{~m}$ at night and 125 to $175 \mathrm{~m}$ at day (Jorgensen 2004). Packing densities of capelin in the Barents Sea vary from (day) 1.4 to 15 and (night) 0.8 to 3.5 fish m ${ }^{-3}$ (Serberov 1985). Using vertical school extents of (day) 50 and (night) $30 \mathrm{~m}$ (Jorgensen 2004), we obtain mean school densities of (day) 70 to 750 and (night) 24 to 105 fish $\mathrm{m}^{-2}$. Capelin body lengths average $16 \mathrm{~cm}$ (Jorgensen 2003, Gauthier \& Horne 2004) (maximum: 20 cm for females, $25 \mathrm{~cm}$ for males; Froese \& Pauly 2009). Capelin are characterized by a shorter swimbladder than most fish with a major axis that is approximately $15 \%$ of their length (Jorgensen 2003, Gauthier \& Horne 2004).

When operating at the resonance peak near $1.2 \mathrm{kHz}$ (Fig. 10), OAWRS should be able to detect capelin schools of a density of 105 fish $\mathrm{m}^{-2}$ (night; Table 1) with an SNR of $30 \mathrm{~dB}$ (Fig. 11). Capelin should then be detectable by OAWRS over a dynamic range of $30 \mathrm{~dB}$ in population density between 105 and 0.1 fish

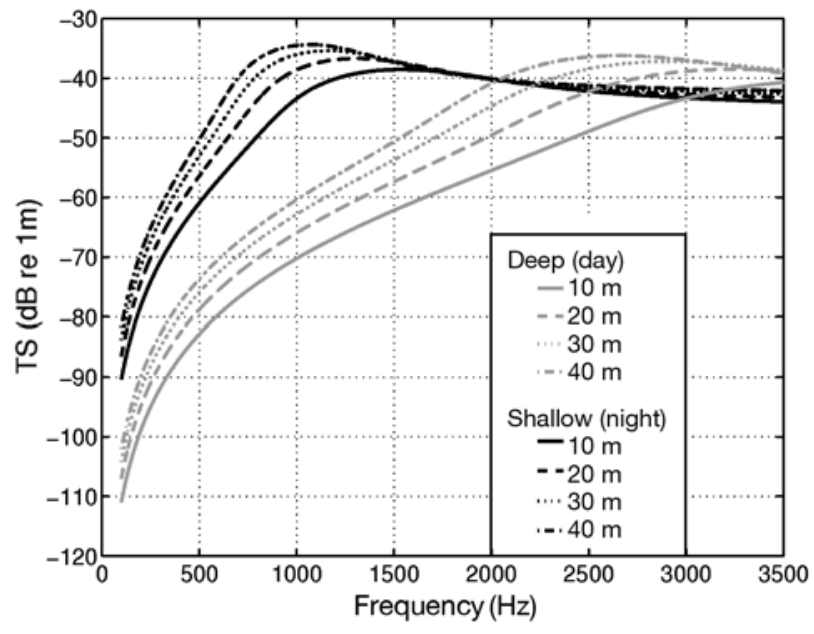

Fig. 10. Mallotus villosus. Modeled target strength (TS) for capelin at 2 different water layers (Table 1) in the Barents Sea, for different neutral buoyancy depths. Shallow (night): black lines; deep (day): grey lines. Same procedure as that employed in Fig. 6

$\mathrm{m}^{-2}$, which is much lower than typical schooling densities. Daytime schools of capelin (750 fish $\mathrm{m}^{-2}$, Table 1) should be detectable by OAWRS at resonance (2.4 kHz) with an SNR of at least $45 \mathrm{~dB}$ (Fig. 11). Daytime schools of capelin should then be detectable by OAWRS over a dynamic range of $45 \mathrm{~dB}$ in population density from 750 to a minimum value of 0.02 fish $\mathrm{m}^{-2}$, which are much lower than typical schooling densities (Table 1).

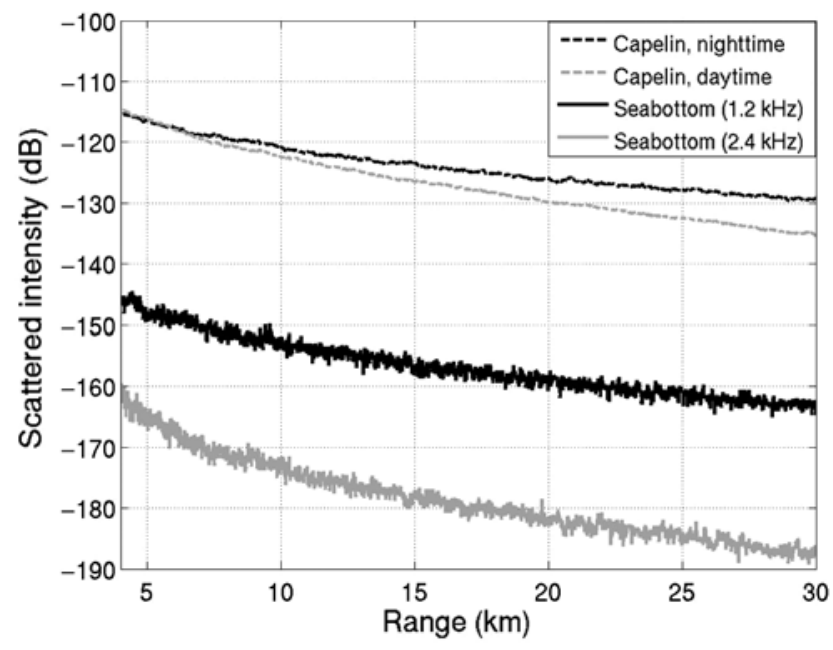

Fig. 11. Mallotus villosus. Scattered intensity from capelin and seabottom modeled at $1.2 \mathrm{kHz}$ (night: black lines) and at $2.4 \mathrm{kHz}$ (day: grey lines). Capelin are assumed to have packing densities of (night) 105 and (day) 750 fish $\mathrm{m}^{-2}$, and to be uniformly distributed in a depth layer (night: 30 to $60 \mathrm{~m}$; day: 125 to 174 ) 


\section{Southern blue whiting Micromesistius australis}

The continental shelf and adjacent waters off Southern Patagonia constitute one of the main fishing grounds of the Argentine Sea. The Southern blue whiting is the most abundant demersal-mesopelagic fish in this region (Cassia 2000), and is the third largest species caught by local fishing fleets (Cassia 2000, Macchi \& Pajaro 2005), after Argentine hake and hoki. Southern blue whiting typically occupy water depths of 100 to $200 \mathrm{~m}$ (Agnew 2002) along the Patagonia continental slope and shelf break and provide a major food source for larger higher-trophic predators, such as Argentine hake, whales, sea lions, as well as sea-birds, including the yellow-eyed penguin and black-browed albatross (Thompson et al. 1998, Cherel et al. 1999, Jackson et al. 2000).

The TS of southern blue whiting is modeled by assuming a uniform vertical distribution over a $50 \mathrm{~m}$ thick layer from 150 to $200 \mathrm{~m}$ depth (Cassia 2000). Since whitings are physoclists, they are expected to be neutrally buoyant over a similar depth range. Trawl samples from typical spawning stocks (Cassia 2000) show a bimodal distribution of lengths associated with age and sex (mean length; male: $39 \mathrm{~cm}_{i}$ female: $51 \mathrm{~cm}$ (Cassia 2000). The areal density of 1 fish $\mathrm{m}^{-2}$ (Table 1) is the average density derived from trawl catches over a large area covering hundreds of $\mathrm{km}^{2}\left(\mathrm{O}^{\prime}\right.$ Driscoll et al. 2005). Southern blue whiting are known to mass in dense aggregations wherein the school densities may be much higher than those reported in Table 1.

When operating at the resonance peak near $800 \mathrm{~Hz}$ (Fig. 12, black lines), OAWRS should be able to detect female-dominated schools of an areal density of 1 fish

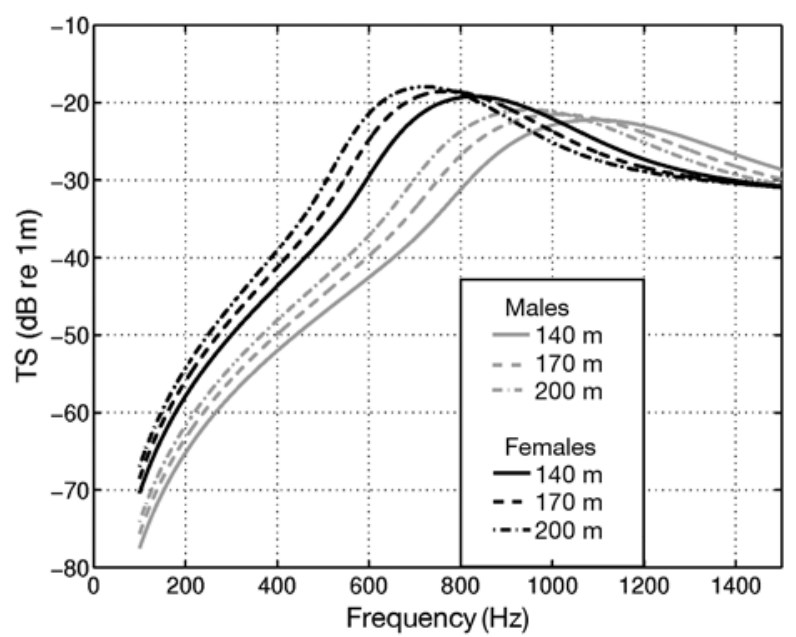

Fig. 12. Micromesistius australis. Modeled target strength (TS) for southern blue whiting in the Argentine-Falklands region for different neutral buoyancy depths. Black lines: female; grey lines: males. Same procedure as that employed in Fig. 6 $\mathrm{m}^{-2}$ with an SNR of $30 \mathrm{~dB}$ (Fig. 13). Female-dominated schools should then be detectable by OAWRS over a dynamic range of at least $30 \mathrm{~dB}$ in population density, from values of 1 to 0.001 fish $\mathrm{m}^{-2}$, which is much lower than typical schooling densities (Table 1). Maledominated shoals of typical density 1 fish $\mathrm{m}^{-2}$ should be detectable by OAWRS at resonance $(\sim 1 \mathrm{kHz}$; Fig 12, grey lines) with an SNR of $25 \mathrm{~dB}$ (Fig. 13). Male-dominated schools should then be detectable by OAWRS over a dynamic range of at least $25 \mathrm{~dB}$ in population density from 1 to a minimum detectable value of 0.003 fish $^{-2}$ which is much lower than typical schooling densities (Table 1). It should then be possible to observe both single males and females up to a range of about $2 \mathrm{~km}$.

\section{Argentine hake Merluccius hubbsi}

Argentine hake is a mid-trophic level species providing forage for whales, sea lions, penguins, sea-birds, and other fauna native to the Patagonian ecosystem (Alonso et al. 2000). Argentine hake are known to feed on smaller fish such as anchovies, juvenile hake, southern blue whiting, squids, and macrozooplankton (FAO 2009). Argentine hake are typically found in the coastal and continental shelf environments of Falkland-Malvinas Islands between the 100 to $200 \mathrm{~m}$ isobaths. Fishing pressures on Argentine hake in the 1990s caused shifts to deeper water and lower density spawning populations (Macchi et al. 2007).

Argentine hake are known to amass in large shoals in coastal waters at depths between 60 and $90 \mathrm{~m}$.

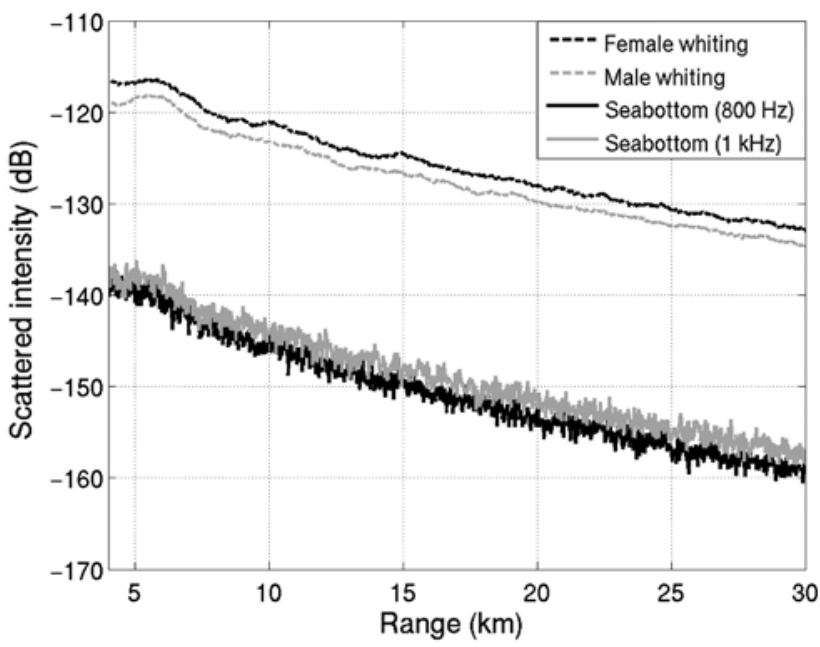

Fig. 13. Micromesistius australis. Scattered intensity from whiting and seabottom modeled at $800 \mathrm{~Hz}$ (female: black lines) and at $1 \mathrm{kHz}$ (male: grey lines). The whiting are assumed to have a packing density of 1 fish $\mathrm{m}^{-2}$, and to be distributed from 150 to $200 \mathrm{~m}$ depth with uniform probability 
Spawning occurs from October to February, with peak activity in January. Early in the spawning season, hake populations are dominated by juveniles of both sexes with a mean length $\sim 28 \mathrm{~cm}$ (Macchi et al. 2007). Towards the end of the spawning season, larger adult hake (mean lengths $\sim 38 \mathrm{~cm}$ ) accumulate along with the juveniles (Macchi et al. 2007). The densities reported in Table 1 are average densities derived from trawl catches over a large area covering $4 \times 10^{4} \mathrm{~km}^{2}$ (Macchi et al. 2007). Hake are known to mass in dense aggregations wherein the school densities may be much higher than those reported in Table 1. Both juvenile and adult hake are physoclist, and are assumed to be neutrally buoyant at 60 to $90 \mathrm{~m}$ depth.

When operating at the resonance peak near $650 \mathrm{~Hz}$ (Fig. 14, black lines), OAWRS should be able to image adult hake shoals of population density of 0.5 fish $\mathrm{m}^{-2}$ (Table 1) with an SNR of $25 \mathrm{~dB}$ (Fig. 15). OAWRS detections of adult hake should then span a dynamic range of at least $25 \mathrm{~dB}$ in population density from 0.5 (Table 1) to a minimum detectable value of 0.002 fish $\mathrm{m}^{-2}$. Above resonance, densities of at least $0.02 \mathrm{fish} \mathrm{m}^{-2}$ are required, but this is still much lower than the average shoaling densities (Table 1), so that OAWRS imagery should span a dynamic range of at least 2 orders of magnitude, or $20 \mathrm{~dB}$, in population density.

Schools of juvenile hake with a population density of 0.3 fish $\mathrm{m}^{-2}$ should be detectable by OAWRS at their resonance of $900 \mathrm{~Hz}$ (grey lines in Fig. 14) with an SNR of $20 \mathrm{~dB}$ (Fig. 15). OAWRS detections of juvenile hake should then span a dynamic range of at least $20 \mathrm{~dB}$ in population density, from 0.3 fish $\mathrm{m}^{-2}$ to a minimum detectable value of 0.003 fish $\mathrm{m}^{-2}$.

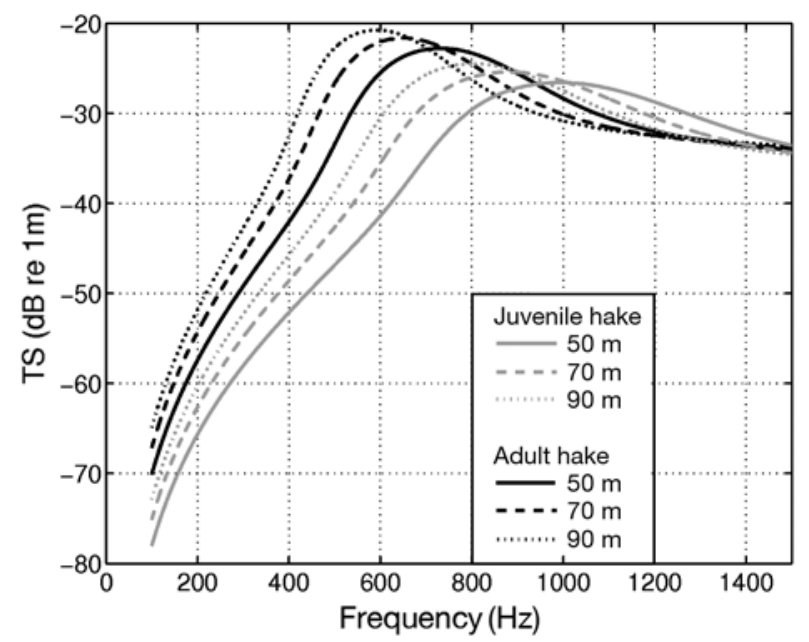

Fig. 14. Merluccius hubbsi. Modeled target strength (TS) for hake in the beginning (corresponding to a majority of juveniles: grey lines) and end (corresponding to a majority of adults: black lines) of the spawning season, off Argentina. Same procedure as that employed in Fig. 6

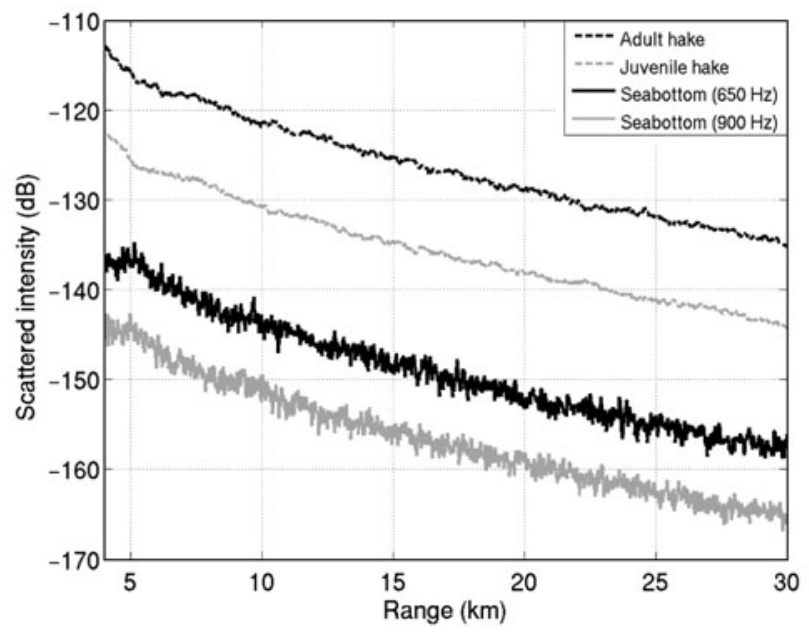

Fig. 15. Merluccius hubbsi. Scattered intensity from hake and seabottom modeled at $650 \mathrm{~Hz}$ (adults: black lines) and $900 \mathrm{~Hz}$ (juveniles: grey lines). During the day, hake are assumed to be uniformly distributed in depth layers (adults: 60 to $90 \mathrm{~m}$, packing density 0.5 fish $\mathrm{m}^{-2}$; juveniles: 60 to $90 \mathrm{~m}$, density 0.3 fish $\mathrm{m}^{-2}$ )

\section{Atlantic bluefin tuna Thunnus thynnus}

Atlantic bluefin tuna are large top-predators that feed on mid-sized fish. Their size and speed allows them to evade most predators, with the exception of sharks, larger toothed whales and humans (Cascorbi \& Chabot 2004). As physoclists, neutral buoyancy is expected at their common swimming depths of 10 to $40 \mathrm{~m}$ (Lutcavage 2000). A typical tuna school is $\sim 20 \mathrm{~m}$ in diameter (Newlands et al. 2006), with an inter-fish separation of 1 body length (areal density of 0.25 fish $\mathrm{m}^{-2}$ ) (Partridge et al. 1983).

For the OAWRS 2003 system, where operating frequencies are above the resonance at $\sim 50 \mathrm{~Hz}$ (Fig. 16),

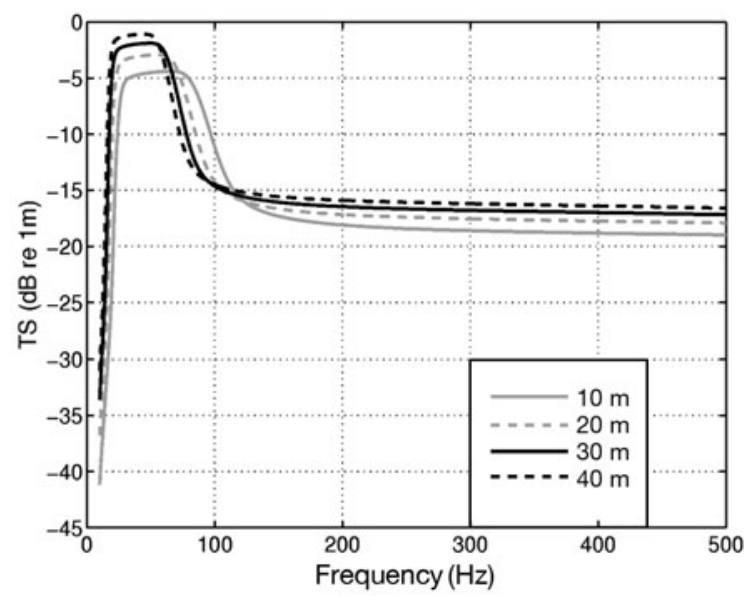

Fig. 16. Thunnus thynnus. Modeled target strength (TS) for bluefin tuna with different neutral buoyancy depths (10 to $40 \mathrm{~m}$ ). Same procedure as that employed in Fig. 6 


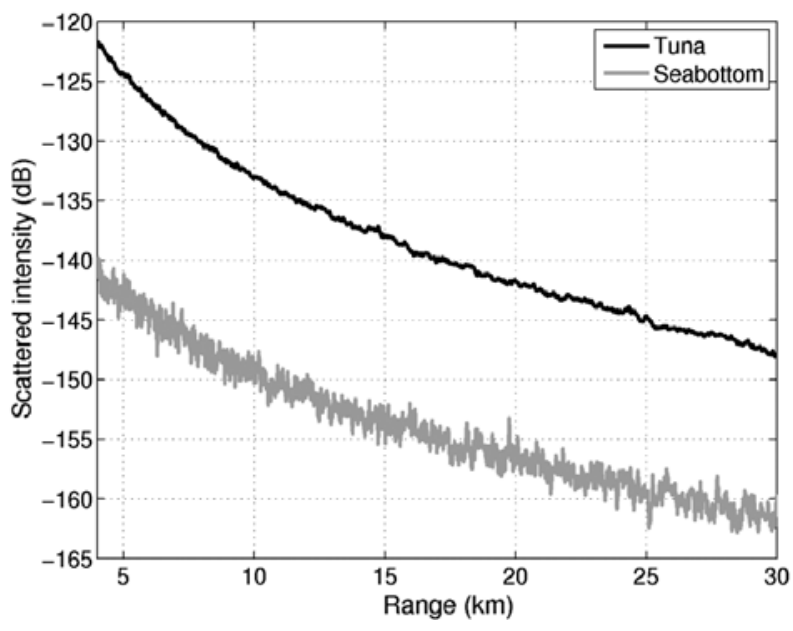

Fig. 17. Thunnus thynnus. Scattered intensity from bluefin tuna and seabottom modeled at $950 \mathrm{~Hz}$. Tuna packing density within an OAWRS resolution footprint is assumed to be rangedependent and is given by the ratio 'area occupied by the tuna school' : 'area of the resolution footprint' $\times$ 'school density of 0.25 fish $\mathrm{m}^{-2}$ '. For example, for the OAWRS 2003 system, the effective density of a school within the OAWRS footprint would be 0.025 fish $\mathrm{m}^{-2}$ at $10 \mathrm{~km}$. At $20 \mathrm{~km}$, the footprint area doubles and the effective density reduces to 0.0125 fish $\mathrm{m}^{-2}$. This is reflected in the figure as a reduction in the signal to noise ratio as the range increases. The tuna are assumed to be uniformly distributed in a layer from 0 to $30 \mathrm{~m}$ water depth

typical tuna schools occupy areas smaller than an OAWRS resolution cell for ranges $>70 \mathrm{~m}$. The effective areal density of a single school within an OAWRS resolution footprint is then given by the ratio: 'area occupied by the tuna school' : 'area of the footprint)' $x$ 'school density of 0.25 fish $\mathrm{m}^{-2}$. For example, at a range of $10 \mathrm{~km}$ the effective areal density is $\sim 0.025$ fish $\mathrm{m}^{-2}$. Since the effective density is a function of the OAWRS resolution footprint area, the SNR varies with range (Fig. 17) from 15 to $20 \mathrm{~dB}$.

An OAWRS system could be designed to operate near resonance $(50 \mathrm{~Hz})$ and with sufficiently high resolution so that the 'area occupied by a single typical tuna school' $\geq$ 'OAWRS resolution cell' (Appendix C). In this scenario, OAWRS could image typical tuna schools with an SNR of $50 \mathrm{~dB}$, given the higher TS and effective density. OAWRS detections of tuna should then span a dynamic range of $50 \mathrm{~dB}$ in population den-

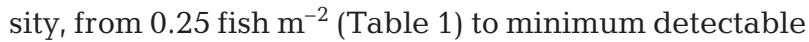
values of $3 \times 10^{-6}$ fish $\mathrm{m}^{-2}$, or $\sim 1$ fish in a $600 \times 600 \mathrm{~m}$ area.

The wide-area spatial coverage and continuous temporal monitoring of OAWRS can be an asset in studying the behavioral dynamics and spatial distributions of fast-swimming, highly migratory pelagic fish. Since bluefin tuna swim at speeds of $4 \mathrm{~km} \mathrm{~h}^{-1}$ (Itoh et al. 2003) and occupy broad geographic scales, they are difficult to survey with conventional methods such as electronic tagging, satellite, or spotter plane aerial imaging which are limited to studying individual fish or surficial populations (Lutcavage 2000, Newlands et al. 2006).

The ability of OAWRS to image and continuously track small, but rapidly swimming schools of marine creatures of $\sim 100 \mathrm{~m}$ extent was demonstrated in 2003 (Makris et al. 2006a,b). For example, a small compact group, located at $9 \mathrm{~km}$ south and $3 \mathrm{~km}$ east of the OAWRS source, was observed traveling north at $\sim 5 \mathrm{~km}$ $\mathrm{h}^{-1}$, consistent with a typical tuna school (Fig. 18). Similar aggregations were observed within a $1.5 \mathrm{~km}$ radius exhibiting the morphological, dynamical spatial distributions, speeds and uniform trajectories typical of fast-swimming tuna schools. The OAWRS-measured densities for these groups of $\sim 5 \times 10^{-4}$ fish $\mathrm{m}^{-2}$, after compensating for the expected TS of an individual at $415 \mathrm{~Hz}(\sim-17 \mathrm{~dB})$, follows expectations for tuna.

\section{Antarctic krill Euphausia superba}

Antarctic krill is widely distributed in the Antarctic ocean (Nicol \& Endo 1997) and plays a key role as the primary source of sustenance for many species of whales, seals, birds, fish and squid (Miller \& Hampton 1989).

It may be possible for OAWRS to detect and image large swarms of krill, given a properly designed OAWRS system (Chen 2008). Krill differs only slightly in compressibility and density from the surrounding seawater as it does not have any gas-filled cavities. This makes krill extremely weak sound scatterers at OAWRS frequencies (Fig. 19) compared to swimbladdered fish. Therefore, krill concentrations need to be much higher than those of swimbladdered fish for successful OAWRS imaging. Fortunately, typical swarm densities of Antarctic krill exceed $10^{3}$ ind. $\mathrm{m}^{-3}$, and can reach up to $10^{5}$ ind. $\mathrm{m}^{-3}$ in superswarms (Hamner \& Hamner 2000). While these high densities help to offset the weak scattering of an individual, effective use of OAWRS to image krill will likely require taking advantage of the vertical sound speed structure of the polar environments. This sound speed structure makes it possible to design an OAWRS system that channels sound in well known and widely used refract-surfacereflected (RSR) paths that do not interact with the seafloor, but only with the ocean-atmosphere interface to form a waveguide (Urick 1983; Supplement 1). Since krill are mainly found in the upper water column $(<100$ m) (Hamner et al. 1983, Brierley \& Watkins 2000, Brierley et al. 2002), RSR paths can insonify the krill well with minimal bottom interference. Long range sensing systems have used purely waterborne refractive paths for remote sensing of submerged objects and 


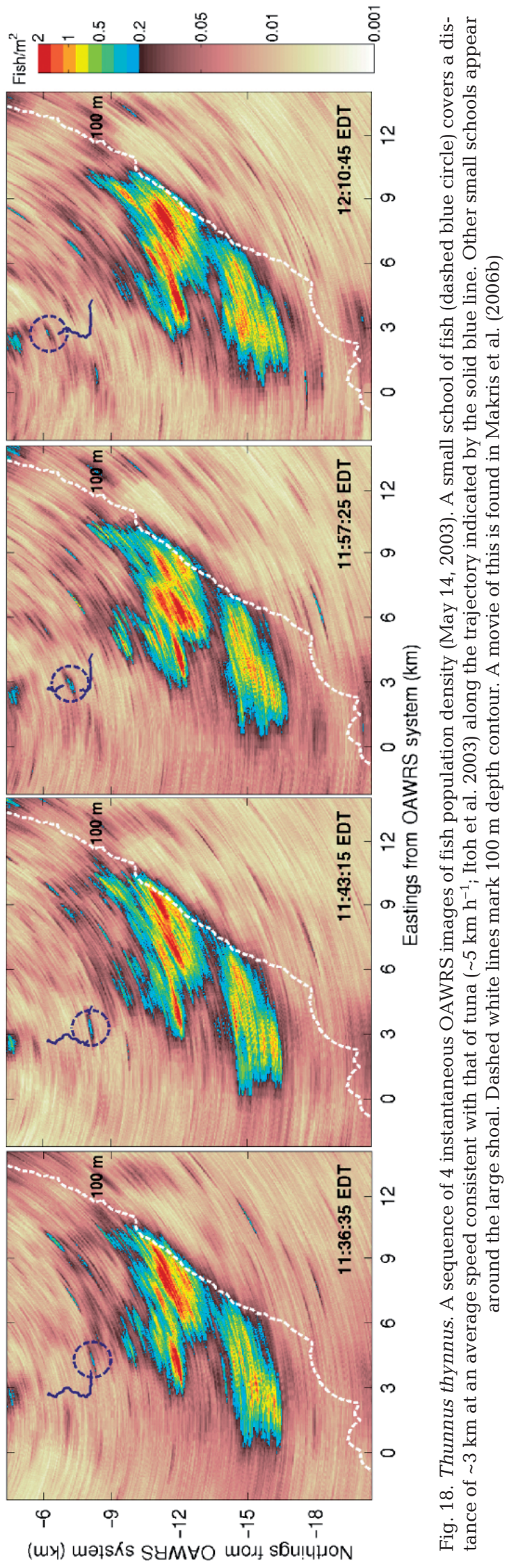

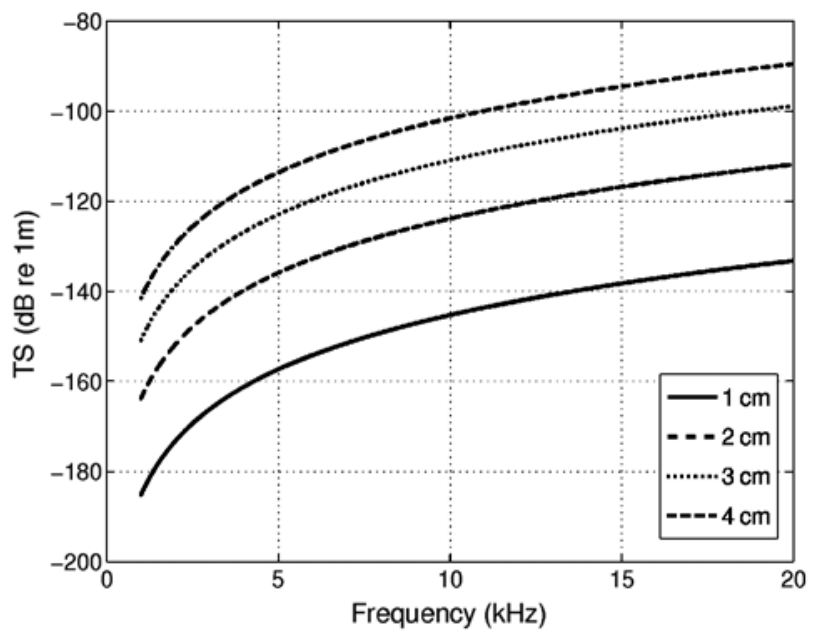

Fig. 19. Euphausia superba. Target strength (TS) for different sizes of krill. The TS is calculated by Rayleigh-Born approximation (Morse \& Ingard 1968) given the geometry and acoustic properties of krill (Lawson et al. 2006)

seamounts in scenarios more challenging than those proposed here. For example, during a field experiment at the Mid-Atlantic Ridge, narrow sound beams were guided by refraction over ranges of $>100 \mathrm{~km}$, to almost graze the ocean bottom and sea surface at ray vertex, pass through narrow ridges and accurately impinge on the preordained geological features under investigation (Makris et al. 1995, ONR 1996, Smith \& Cushman 1997, Harding et al. 1998, Preston 2000, Medwin 2005).

The scattered field from krill is compared with seafloor scattering at $10 \mathrm{kHz}$ in Fig. 20 for both deep ocean $(2000 \mathrm{~m})$ and continental shelf environments (200 m).

An OAWRS system operating at $10 \mathrm{kHz}$ should be able to detect swarms of $2 \mathrm{~cm}$ krill at a range of $5 \mathrm{~km}$ when their packing density is $>0.1$ ind. $\mathrm{m}^{-3}$ for deep and $>1$ ind. $\mathrm{m}^{-3}$ for shallow waters. Since typical swarming densities are much higher, OAWRS should be able to image typical krill swarms with a dynamic range of at least $40 \mathrm{~dB}$ for deep ocean, and $30 \mathrm{~dB}$ for continental shelf environments (Fig. 20).

For smaller krill of $1 \mathrm{~cm}$ length, OAWRS imaging is expected to be less favorable in continental-shelf environments, unless densities are at least $10^{5}$ ind. $\mathrm{m}^{-3}$ (superswarms, see above). A transmitter array with lower sidelobe levels may resolve this problem even for typical densities of 1000 ind. $\mathrm{m}^{-3}$.

\section{Summary}

The dynamic range expected in OAWRS imaging is summarized in Fig. 21 for a variety of ecologically significant fish species, and in Fig. 22 for Antarctic krill. 


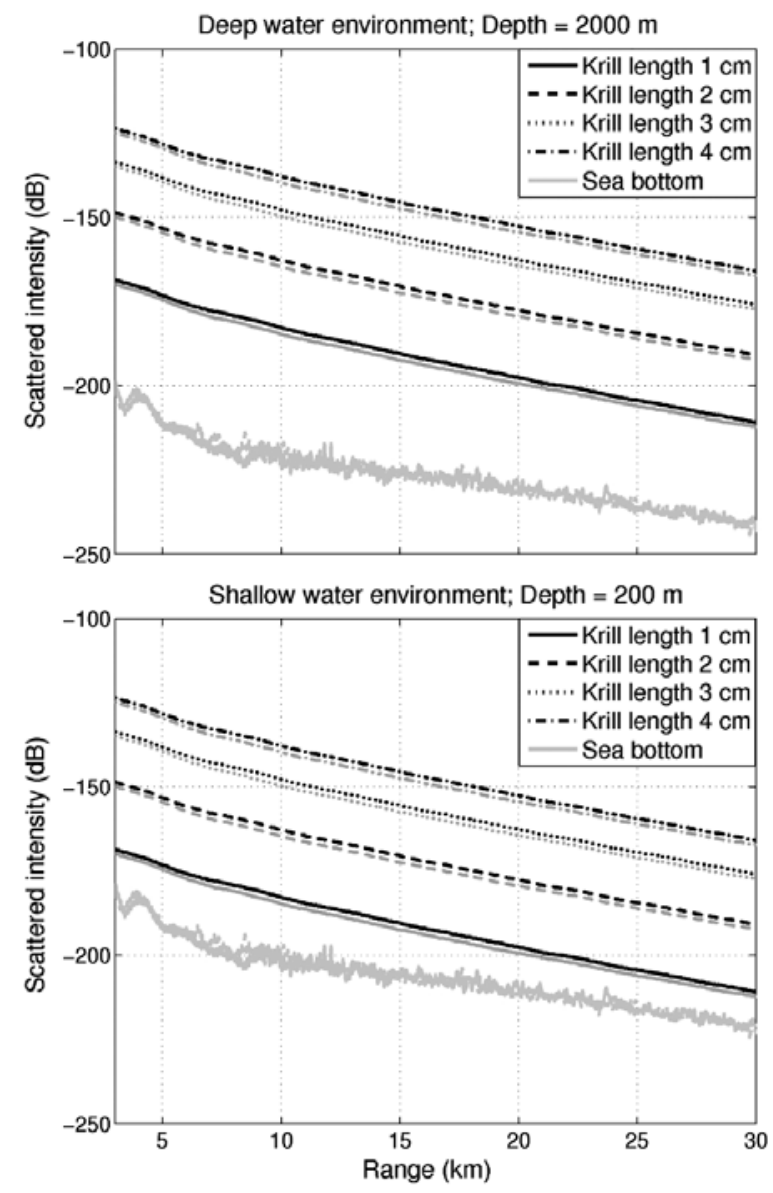

Fig. 20. Euphausia superba. Scattered intensity from krill and seabottom for (a) deep ocean and (b) continental shelf environments. Krill individuals are assumed to have lengths from 1 to $4 \mathrm{~cm}$, a typical packing density of 1000 ind. $\mathrm{m}^{-3}$ (Hamner \& Hamner 2000), and a uniform distribution from 0 to $100 \mathrm{~m}$ depth. Black and grey lines correspond to scattered intensity computed using the winter and summer profiles in Supplement 1 Fig. S2, respectively

For all fish species examined, typical shoaling densities (Fig. 21) are at least 2 orders of magnitude greater than the minimum densities detectable by OAWRS, making them viable candidates for future wide-area surveys. For Antarctic krill of at least $2 \mathrm{~cm}$ length, OAWRS should be capable of imaging typical swarming densities (Fig. 22) with a dynamic range at least 2 orders of magnitude. With appropriate system design, it may be possible to image smaller krill with OAWRS.

\section{CONCLUSIONS}

We reviewed a number of recent findings in marine ecology related to the behavior of vast oceanic fish shoals that were made possible by Ocean Acoustic Waveguide Remote Sensing (OAWRS), a technique

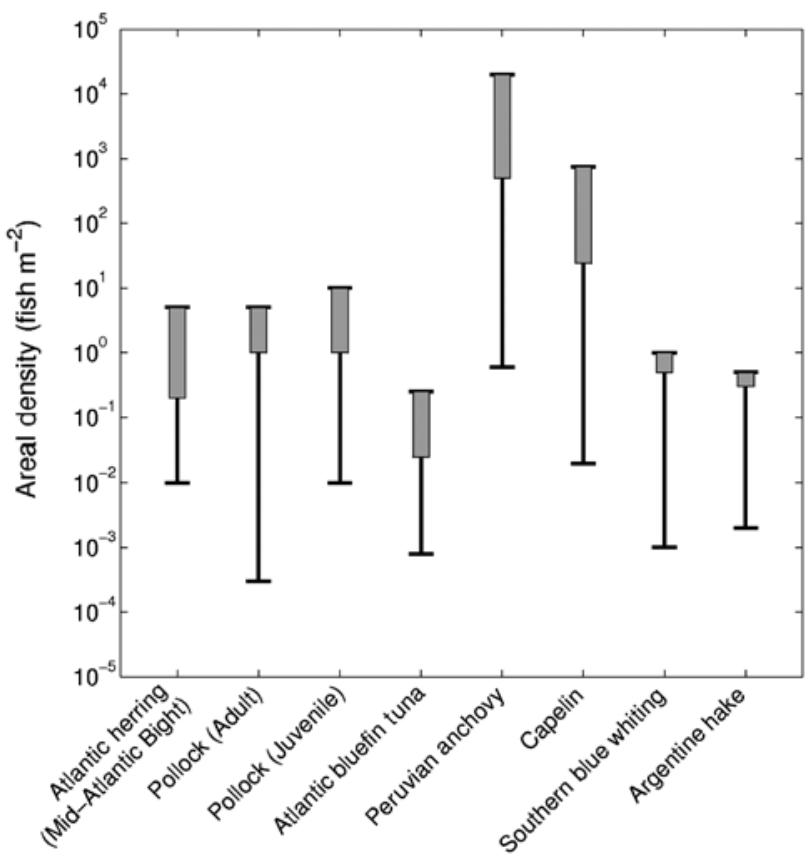

Fig. 21. Comparison of dynamic ranges in population density expected in wide-area surveys for the 8 fish species discussed. Lower end of vertical bar $=$ expected minimum individual densities observable with OAWRS. Upper end = maximum areal fish densities from historical observations. Shaded: typical shoaling density from historical observations

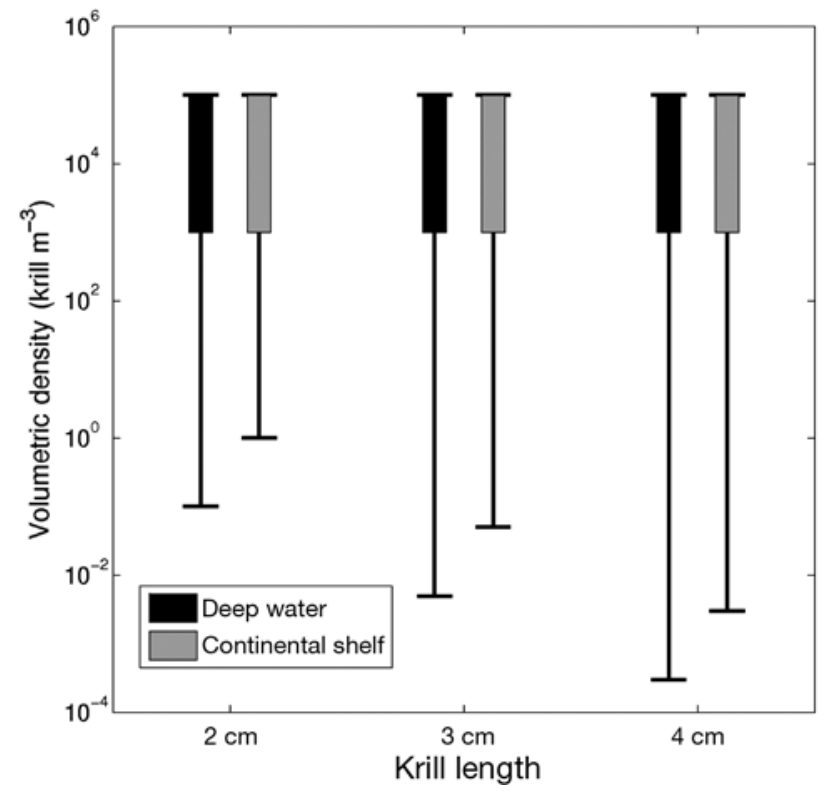

Fig. 22. Expected dynamic range in population density for Antarctic krill as a function of length in wide-area surveys. Lower end of vertical bar = expected minimum individual density observable with OAWRS from modeling and simulation (Chen 2008). Upper end = maximum densities from historical observations. Shaded = typical swarming densities from historical observations 
capable of instantaneously imaging and continuously monitoring fish populations over continental shelf-scale areas, spanning thousands of $\mathrm{km}^{2}$. OAWRS can be used in oceanic ecosystems to remotely assess populations and study the behavior of fish and other marine organisms such as Antarctic krill. The approaches presented here for wide-area and continuous-time monitoring of pelagic species may help to meet the significant demands of the ecosystem-based approach to research and conservation in marine biology (Garcia \& Cochrane 2001, Pikitch et al. 2004, Browman \& Stergiou 2004, Stergiou \& Browman 2005).

Currently, OAWRS has been deployed from moving research vessels. In the future, it will likely also be deployed at fixed locations to enable continuous long term monitoring of oceanic ecosystems and their variations. A precedent already exists for this in the atmosphere where fixed Doppler-weather radar (DWR) stations have been used to instantaneously image bird populations and study population distributions, migrations and behavior over wide areas. Continuous DWR monitoring has been instrumental in avian conservation and ecosystem-based resource management (Gauthreaux \& Belser 2003, 2005, Ruth et al. 2005). With frequent use, OAWRS can likewise play a significant role in scientific exploration, ecosystem management and conservation in the world's oceans.

Acknowledgements. This research was supported by the Office of Naval Research, the Alfred P. Sloan Foundation, and the National Oceanographic Partnership Program, and is a contribution to the Census of Marine Life.

\section{LITERATURE CITED}

Agnew DJ (2002) Critical aspects of the Falkland Islands pelagic ecosystem: distribution, spawning and migration of pelagic animals in relation to oil exploration. Aquat Conserv: Mar Freshw Ecosyst 12:39-50

Alonso MK, Crespo EA, Pedraza SN, Garcia NA, Coscarella MA (2000) Food habits of the South American sea lion, Otaria flavescens, off Patagonia, Argentina. Fish Bull (Wash DC) 98:250-263

Andreeva IB (1964) Scattering of sound by air bladders of fish in deep sound-scattering ocean layers. Akust Zh 10:20-24 (English translation in Soviet Phys-Acoust 10:17-20)

Andreeva IB (1965) Acoustical characteristics of sonic scattering layers in ocean. Proc 5th Int Congr Acoustics, Liège, 1A: paper E68

Andreeva IB, Chindonova YG (1964) On the nature of soundscattering layers. Okeanologiya 1:112-124

Andrews M, Gong Z, Cocuzzo D, Ratilal P (2009a) Population density imaging of random scatterers with the matched filtered scattered field variance. J Acoust Soc Am 126: 1057-1068

Andrews M, Chen T, Ratilal P (2009b) Empirical dependence of acoustic transmission scintillation statistics on bandwidth, frequency, and range in New Jersey continental shelf. J Acoust Soc Am 125:111-124
Argo Database (2009) International Argo Project. Accessed 20 May at www.argo.ucsd.edu, http://argo.jcommops.org.

Balls R (1948) Herring fishing with the echometer. J Cons Int Explor Mer 15:193-206

Balls R (1951) Environmental changes in herring behavior: a theory of light avoidance, as suggested by echo-sounding observations in the North Sea. J Cons Int Explor Mer 17: 274-298

Bergmann PG (1948) Intensity fluctuations. In: The physics of sound in the sea, Part 1: Transmission. National Defense Research Committee, Washington DC

Blanco JL, Barría P, Castillo J, Atkinson LP (2002) Response of anchovy (Engraulis ringens) off northern Chile to the 1997-1999 El Niño-La Niña sequence. Investig Mar Valparaiso 30:107-108

Blaxter JHS, Batty RS (1984) The herring swimbladder: loss and gain of gas. J Mar Biol Assoc UK 64:441-459

Blaxter JHS, Tytler P (1978) Physiology and function of the swimbladder. Adv Comp Physiol Biochem 7:311-367

Bouchon M, Díaz E, Cahuín S, Ochoa M (2002) Effects of El Niño 1997-98 on the schooling behaviour of the Peruvian anchovy (Engraulis ringens). Investig Mar Valparaiso 30:182-183

Brawn VM (1962) Physical properties and hydrostatic function of the swimbladder of herring (Clupea harengus L.). J Fish Res Board Can 19:635-656

Brekhovskikh LM, Lysanov YuP (1991) Fundamentals of ocean acoustics. In: Felsen LB (ed) Wave phenomena. Springer-Verlag, Heidelberg

Brierley AS, Watkins JL (2000) Effect of sea ice cover on swarming behaviour of Antarctic krill, Euphasia superba. Can J Fish Aquat Sci 57(Suppl 3):24-30

Brierley AS, Fernandes PG, Brandon MA, Armstrong F and others (2002) Antarctic krill under sea ice: Elevated abundance in a narrow band just south of ice edge. Science 295:1890-1892

> Browman HI, Stergiou KI (2004) Marine Protected Areas as a central element of ecosystem-based management: defining their location, size and number. Mar Ecol Prog Ser 274:271-272

> Bucker H (1970) Sound propagation in a channel with lossy boundaries. J Acoust Soc Am 48:1187-1194

> Buckingham MJ, Tolstoy A (1990) An analytical solution for benchmark problem 1: The 'ideal' wedge. J Acoust Soc Am 87:1511-1513

Buhl J, Sumpter DJT, Couzin ID, Hale J, Despland E, Miller E, Simpson SJ (2006) From disorder to order in marching locusts. Science 312:1402-1406

Cascorbi A, Chabot H (2004) Seafood report. Tunas, Vol II: Atlantic bluefin tuna, Northeast Region. Final report, July 19, 2004. Seafood Watch, Monterey Bay Aquarium, Monterey, CA

Cassia MC (2000) Age and growth of the southern blue whiting Micromesistius australis in the SW Atlantic. Sci Mar 64:269-274

Chen T (2008) Mean, variance, and temporal coherence of the 3D acoustic field forward propagated through random inhomogeneities in continental-shelf and deep ocean waveguides. PhD dissertation, Massachusetts Institute of Technology, Cambridge, MA

- Chen T, Ratilal P, Makris NC (2005) Mean and variance of the forward field propagated through three-dimensional random internal waves in a continental-shelf waveguide. J Acoust Soc Am 118:3560-3574

Chen T, Ratilal P, Makris NC (2008) Temporal coherence after multiple forward scattering through random threedimensional inhomogeneities in an ocean waveguide. 
J Acoust Soc Am 124:2812-2822

Cherel Y, Waugh S, Hanchet S (1999) Albatross predation of juvenile southern blue whiting on Campbell Plateau. N Z J Mar Freshw Res 33:437-441

Clay CS, Medwin H (1977) Acoustical oceanography: principles and applications. John Wiley \& Sons

Collins MD (1990) Benchmark calculations for higher-order parabolic equations. J Acoust Soc Am 87:1535-1538

Collins MD (1993) A split padé solution for the parabolic equation method. J Acoust Soc Am 93:1736-1742

Conti SG, Demer DA (2003) Wide-bandwidth acoustical characterization of anchovy and sardine from reverberation measurements in an echoic tank. ICES J Mar Sci 60: $617-624$

Couzin ID, Krause J, Franks NR, Levin SA (2005) Effective leadership and decision making in animal groups on the move. Nature 433:513-516

Cury P, Shannon L, Shin YJ (2001) The functioning of marine ecosystems. Reykjavik Conf on Responsible Fisheries in the Marine Ecosystem. Reykjavik, Iceland, 1-4 Oct, 2001. Accessed 26 Feb 2009. at ftp://ftp.fao.org/fi/document/ reykjavik/pdf/07Cury.pdf

$>$ Dahl P, Mathisen O (1983) Measurement of fish target strength and associated directivity at high frequencies. J Acoust Soc Am 73:1205-1211

Duvall GE, Christensen RJ (1946) Stratification of sound scatterers in the ocean. J Acoust Soc Am 18:254

$>$ Dwyer DA, Bailey KM, Livingston PA (1987) Feeding habits and daily ration of Walleye pollock (Theragra chalcogramma) in the Eastern Bering Sea, with special reference to cannibalism. Can J Fish Aquat Sci 44:1972-1984

$>$ Dyer I (1970) Statistics of sound propagation in the ocean. J Acoust Soc Am 48:337-345

Dyson F, Munk W, Zetler B (1976) Interpretation of multipath scintillations to Eleuthera to Bermuda in terms of internal waves and tides. J Acoust Soc Am 59:1121-1133

Ellis D (1995) A shallow-water normal-mode reverberation model. J Acoust Soc Am 97:2804-2814

Ewing M, Worzel JL (1948) Long range sound transmission. Geol Soc Am Mem 27

Eyring CF, Christensen RJ, Raitt RW (1948) Reverberation in the sea. J Acoust Soc Am 20:462-475

FAO (Food and Agriculture Organisation) (1997) Review of the state of world aquaculture. FAO Fisheries Circular No. 886, Rev. 1. FAO, Rome

FAO (Food and Agriculture Organisation) (2009) Species fact sheets. Merluccius hubbsi (Marini, 1933). FAO Fisheries \& Aquaculture, Rome. Accessed Feb 26, 2009 at www.fao. org/fishery/species/3027

Farmer DM, Trevorrow MV, Pedersen B (1999) Intermediate range fish detection with a $12 \mathrm{kHz}$ sidescan sonar. J Acoust Soc Am 106:2481-2490

Fredricks A, Colosi JA, Lynch JF, Gawarkiewicz G, Chiu CS, Abbot P (2005) Analysis of multipath scintillations from long range acoustic transmissions on the New England continental slope and shelf. J Acoust Soc Am 117: 1038-1057

Freon P, Misund OA (1999) Dynamics of pelagic fish distribution and behavior: effects on fisheries and stock assessment. Fishing news books. Blackwell Publishing, Oxford

Frisk GV (1994) Ocean and seabed acoustics: a theory of wave propagation, Prentice Hall, Upper Saddle River, NJ

Froese R, Pauly D (eds) (2009) FishBase. Accessed 26 Feb 2009. www.fishbase.org/Summary/SpeciesSummary.php? id $=252 \&$ CFID $=56355689 \&$ CFTOKEN $=78718322$

- Galinde A, Donabed N, Andrews M, Lee S, Makris NC, Ratilal P (2008) Range-dependent waveguide scattering model calibrated for bottom reverberation in a continental shelf environment. J Acoust Soc Am 123:1270-1281

Garcia SM, Cochrane KL (2001) Fisheries topics. Governance. The ecosystem approach to fisheries management. FAO Fisheries and Aquaculture Department, Rome. Accessed 27 May 2009 at www.fao.org/fishery/topic/13261/en

Gauthier S, Horne JK (2004) Acoustic characteristics of forage fish species in the Gulf of Alaska and Bering Sea based on Kirchoff approximation models. Can J Fish Aquat Sci 61: 1839-1850

Gauthreaux SA Jr, Belser CG (2003) Radar ornithology and biological conservation. Auk 120:266-277

Gauthreaux SA Jr, Belser CG (2005) Radar ornithology and conservation of migratory birds. USDA Forest Service Gen Tech Rep 191: 871-875

Gjosaeter H (1998) The population biology and exploitation of capelin (Mallotus villosus) in the Barents Sea. Sarsia 83: 453-496

Godø OR (2009) Technology answers to the requirements set by the ecosystem approach. In: Beamish RJ, Rothschild BJ (eds) The future of fisheries science in North America. Fish and Fisheries series, Vol 31. Springer Science + Business Media B.V., Heidelberg, p 373-403

Goodman JW (1985) Statistical optics. Wiley, New York

Graves J (1977) Photographic method for measuring spacing and density within anchovy, Engraulis mordox, school groups. Fish Bull (Wash DC) 75:679-685

Gutierrez M, Swartzman G, Bertrand A, Bertrand S (2007) Anchovy (Engraulis ringens) and sardine (Sardinops sagax) spatial dynamics and aggregation patterns in the Humboldt Current ecosystem, Peru, from 1983-2003. Fish Oceanogr 16:155-168

- Hamner WH, Hamner PP (2000) Behavior of Antarctic krill (Euphausia superba): schooling, foraging, and antipredatory behavior. Can J Fish Aquat Sci 57(Suppl. 3):192-202

> Hamner WM, Hamner PP, Strand SW, Gilmer RW (1983) Behavior of Antarctic krill, Euphausia superba: chemoreception, feeding, schooling and molting. Science 220: 433-435

Harden Jones FR, Scholes P (1985) Gas secretion and resorption in the swimbladder of the cod Gadus morhua. J Comp Physiol 155:319-331

> Harding AJ, Hedlin MAH, Orcutt JA (1998) Migration of backscatter data from the Mid-Atlantic Ridge. J Acoust Soc Am 103:1787-1803

Hersey JB, Backus RH (1962) Sound scattering by marine organisms. In: Hill MN (ed) The sea, Vol 1, Chapter 13. Interscience Publications, New York

Hersey JB, Backus R, Hellwig J (1962) Sound-scattering spectra of deep scattering layers in the Western North Atlantic Ocean. Deep-Sea Res 8:196-210

$>$ Hines PC, Crowe DV, Ellis DD (1998) Extracting in-plane bistatic scattering information from a monostatic experiment. J Acoust Soc Am 104:758-768

Holliday D, Larsen H (1979) Thickness and depth distribution of some epipelagic fish schools off southern California. Fish Bull (Wash DC) 77:489-494

Hollowed AB, Wilson CD, Stabeno PJ, Salo SA (2007) Effect of ocean conditions on the cross-shelf distribution of walleye pollock (Theragra chalcogramma) and capelin (Mallotus villosus). Fish Oceanogr 16:142-154

Hsu CC, Liu HC, Wu CL, Huang ST, Liao HK (2000) New information on age composition and length-weight relationship of bluefin tuna, Thunnus thynnus, in the southwestern North Pacific. Fish Sci 66:485-493

> Huntley ME, Zhou M (2004) Influence of animals on turbulence in the sea. Mar Ecol Prog Ser 273:65-79 
Huse I, Ona E (1996) Tilt angle distribution and swimming speed of overwintering Norwegian spring spawning herring. ICES J Mar Sci 53:863-873

Isaacs JD, Schwartzlose RA (1965) Migrant sound scatterers: interaction with the sea floor. Science 150:1810-1813

Itoh T, Tsuji S, Nitta A (2003) Migration patterns of young Pacific bluefin tuna (Thunnus orientalis) determined with archival tags. Fish Bull (Wash DC) 101:514-534

> Jackson GD, Buxton NG, George MJA (2000) Diet of the southern opah Lampris immaculatus on the patagonian shelf; the significance of the squid Morotenthis ingens and anthropogenic plastic. Mar Ecol Prog Ser 206:261-271

Jackson JBC, Kirby MX, Berger WH, Bjorndal KA and others (2001) Historical overfishing and the recent collapse of coastal ecosystems. Science 293:629-637

> Jensen FB, Ferla CM (1990) Numerical solutions of rangedependent benchmark problems in ocean acoustics. J Acoust Soc Am 87:1499-1510

Jensen FB, Kuperman WA, Porter MB, Schmidt H (2000) Computational ocean acoustics. Springer-Verlag, New York

$>$ Jones FRH, Marshall NB (1953) The structure and functions of the teleostean swimbladder. Biol Rev Camb Philos Soc 28:16-82

> Jorgensen R (2003) The effects of swimbladder size, condition and gonads on the acoustic target strength of mature capelin. ICES J Mar Sci 60:1056-1062

Jorgensen R (2004) The effects of behaviour on the acoustic target strength of capelin (Mallotus villosus) and implications for acoustic abundance estimation. Dr Sci thesis, Norwegian College of Fishery Science, University of Tromso

Kay SM (1993) Fundamentals of statistical signal processing. McGraw-Hill

Lawson GL, Wiebe PH, Ashjian CJ, Chu D, Stanton TK (2006) Improved parameterization of Antarctic krill target strength models. J Acoust Soc Am 119:232-242

> Love RH (1993) A comparison of volume scattering strength data with model calculations based on quasisynoptically collected fishery data. J Acoust Soc Am 94:2255-2268

Lutcavage ME, Brill RW, Skomal GB, Chase BC, Goldstein JL, Tutein J (2000) Tracking adult north atlantic bluefin tuna (Thunnus thynnus) in the northwestern Atlantic using ultrasonic telemetry. Mar Biol 137:347-358

Lynch JF, Newhall AE, Sperry B, Gawarkiewicz G and others (2003) Spatial and temporal variation in acoustic propagation characteristics at the New England shelfbreak front. IEEE J Oceanic Eng 28:129-150

Macchi GJ, Pajaro M (2005) Batch fecundity and spawning frequency of southern blue whiting (Micromesistius australis) in the southwest Atlantic ocean. N Z J Mar Freshw Res 39:993-1000

Macchi GJ, Pajaro M, Dato C (2007) Spatial variation of the Argentine hake (Merluccius hubbsi (Marini, 1933)) spawning shoals in the patagonian area during a reproductive Season. Rev Biol Mar Oceanogr 42:345-356

Makris NC (1995) A foundation for logarithmic measures of fluctuating intensity in pattern recognition. Opt Lett 20: 2012-2014

Makris NC (1996) The effect of saturated transmission scintillation on ocean acoustic intensity measurements. J Acoust Soc Am 100:769-783

Makris NC (ed) (2003) Geoclutter acoustics experiment 2003 cruise report. Massachusetts Institute of Technology, Cambridge, MA

Makris NC, Ratilal P (2001) A unified model for reverberation and submerged object scattering in a stratified ocean waveguide. J Acoust Soc Am 109:909-941
Makris NC, Avelino LZ, Menis R (1995) Deterministic reverberation from ocean ridges. J Acoust Soc Am 97:3547-3574

- Makris NC, Ratilal P, Symonds DT, Jagannathan S, Lee S, Nero RW (2006a) Fish population and behavior revealed by instantaneous continental shelf-scale imaging. Science 311:660-663

Makris NC, Ratilal P, Symonds DT, Jagannathan S, Lee S, Nero RW (2006b) Fish population and behavior revealed by instantaneous continental shelf-scale imaging. Science 311, online supporting material. Accessed 27 May. www. sciencemag.org/cgi/content/full/sci;311/5761/660/DC1

- Makris NC, Ratilal P, Jagannathan S, Gong Z and others (2009a) Critical population density triggers rapid shoal formation in vast oceanic fish shoals. Science 323:1734-1737

Makris NC, Ratilal P, Jagannathan S, Gong Z and others (2009b) Critical population density triggers rapid shoal formation in vast oceanic fish shoals. Science 323, online supporting material. Accessed 27 May. www.sciencemag. org/cgi/content/full/sci;323/5922/1734/DC1

Marshall NB (1951) Bathypelagic fishes as sound scatterers in the ocean. J Mar Res 10:1-17

Marshall JR, Chapman RP (1964) Reverberation from a deep scattering layer measured with explosive sound sources. J Acoust Soc Am 36:164-167

McClatchie S, Macauley G, Hanchet S, Coombs RF (1998) Target strength of southern blue whiting (Micromesistius australis) using swimbladder modelling, split beam and deconvolution. ICES J Mar Sci 55:482-493

Medwin H (2005) Sounds in the sea. Cambridge University Press, Cambridge

Medwin H, Clay C (1998) Fundamentals of acoustical oceanography. Academic Press, Boston

Miller DG, Hampton I (1989) Biology and ecology of the Antarctic krill (Euphausia superba Dana): a review. Biomass Sci Ser 9:1-66

Misund OA (1997) Underwater acoustics in marine fisheries and fisheries research. Fish Biol Fish 7:1-34

Morse PM, Ingard KU (1968) Theoretical acoustics. McGrawHill, New York

Munk WH, Worcester P, Wunsch C (1995) Ocean acoustic tomography, Cambridge University Press, Cambridge

Myers RA, Worms B (2003) Rapid worldwide depletion of predatory fish communities. Nature 423:280-283

NEFSC Resource Survey Report (2003) Spring bottom trawl survey. National Marine Fisheries Service. Accessed on 26 Feb, 2009 at www.nefsc.noaa.gov/esb/index.html

> Nero RW, Huster ME (1996) Low-frequency acoustic imaging of Pacific salmon on the high seas. Can J Fish Aquat Sci 53:2513-2523

Nero RW, Thompson CH, Love R (1998) Low-frequency acoustic measurements of Pacific hake, Merluccius productus, off the west coast of the United States. Fish Bull (Wash DC) 96:329-343

> Nero RW, Thompson CH, Jech JM (2004) In situ acoustic estimates of the swimbladder volume of Atlantic herring (Clupea harengus). ICES J Mar Sci 61:323-337

> Newlands NK, Lutcavage ME, Pitcher TJ (2006) Atlantic bluefin tuna in the Gulf of Maine, I: estimation of seasonal abundance accounting for movement, school and schoolaggregation behaviour. Environ Biol Fishes 77:177-195

Nicol S, Endo Y (1997) Krill fisheries of the world. FAO Fish Tech Pap 367

Niquen M, Diaz E (2001) Advances in research on the spatial distribution of anchovy and sardine off the Peruvian coast. Accessed on 26 Feb 2009. sea.uct.ac.za/idyle/seminar/ Spac_Idyle_Envifish_09-2001/presentations/Niquen_and_ Diaz_all.doc 
Niquen M, Freon P (2006) A new record set by the Peruvian fishery: 2.5 million tonnes of anchovy landed in November 2005. Globec Int Newsl 12:56

O'Driscoll RL, Grimes PJ, Hanchet SM, Dunford A (2005) Acoustic estimates of southern blue whiting from the Campbell Island Rise, August-September 2004. N Z Fish Assess Rep 2005/41

Officer CB (1958) Introduction to the theory of sound transmission. McGraw-Hill, New York

ONR (1996) investing in the future 1946-1996: Office of Naval Research 50th Anniversary. ONR, Washington, DC

Partridge BL, Johansen J, Kalish J (1983) School structure of giant bluefin tuna in Cape Cod Bay. Environ Biol Fish 9:253-262

Pikitch EK, Santora C, Babcock EA, Bakun A and others (2004) Ecosystem-based fishery management. Science 305:346-347

Pitcher TJ, Parrish J (1993) The behavior of teleost fishes. Chapman and Hall, London

Pitcher TJ, Partridge BL (1979) Fish school density and volume. Mar Biol 54:383-394

Porter MB, Reiss EL (1985) A numerical method for bottom interacting ocean acoustic normal modes. J Acoust Soc Am 77:1760-1767

Preston JR (2000) Reverberation at the Mid-Atlantic ridge during the 1993 ARSRP experiment seen by R/V Alliance from $200-1400 \mathrm{~Hz}$ and some modeling inferences. J Acoust Soc Am 107:237-259

Radakov DV (1973). Characteristics and biological importance of schools. In: Schooling in the ecology of fish. Wiley, New York, p 77-99

Raitt RW (1948) Sound scatterers in the sea. J Mar Res 7: 393-409

Ratilal P, Makris NC (2005) Mean and covariance of the forward field propagated through a stratified ocean waveguide with three-dimensional random inhomogeneities. J Acoust Soc Am 118:3532-3559

Ratilal P, Lai Y, Makris NC (2002) Validity of the sonar equation and Babinet's principle for scattering in a stratified medium. J Acoust Soc Am 112:1797-1816

Ratilal P, Lai Y, Symonds DT, Ruhlmann LA and others (2005) Long range acoustic imaging of the continental shelf environment: the acoustic clutter reconnaissance experiment 2001. J Acoust Soc Am 117:1977-1998

Reebs SG (2000) Can a minority of informed leaders determine the foraging movements of a fish shoal? Anim Behav 59:403-409

Rusby JSM, Somers ML, Revie J, McCartney BS, Stubbs AR (1973) An experimental survey of a herring fishery by long-range sonar. Mar Biol 22:271-292

Ruth JM, Barrow WC, Sojda RS, Dawson DK and others (2005) Advancing migratory bird conservation and management by using radar: an interagency collaboration. US Geological Survey. Open-File Report 2005-1173

Serberov LI (1985) In: Gjosaeter H (ed) Proc SovietNorwegian Symp on the Barents Sea Capelin. Institute of Marine Research, Bergen, p 135-147

Shaw E (1970) Schooling in fishes: critique and review. In: Aronson LR, Tobach E, Lehrman DS, Rosenblatt JS (eds) Development and evolution of behavior. Freeman, San Francisco, p 452-480

Simmonds EJ, MacLennan DN (2005) Fisheries acoustics, 2nd edn. Chapman and Hall, London

Smith P (1970) The horizontal dimensions and abundance of fish schools in the upper mixed layer as measured by sonar. In: Farquhar G (ed) Int Symp on Sound Scattering in the Ocean. Department of the Navy, Washington DC, p 563-591

Smith KB, Cushman EB (1997) A comparison of quasi-continuous wave and broadband travel time techniques in the prediction of long-range reverberation. J Acoust Soc Am 102:2063-1071

Stephen RA (1990) Solutions to range-dependent benchmark problems by the finite-difference method. J Acoust Soc Am 87:1527-1534

Stergiou KI, Browman HI (2005) Bridging the gap between aquatic and terrestrial ecology-Introduction. Mar Ecol Prog Ser 304:271-272

Stokesbury KDE, Kirsch J, Brown ED, Thomas GL, Notcross BL (2000) Spatial distributions of Clupea pallasi and Theragra chalcogramma. Fish Bull (Wash DC) 98:400-409

Sund O (1935) Echo sounding in fishery research. Nature 135:953

Sundnes G, Sand O (1975) Studies of a physostome swimbladder by resonance frequency analyses. J Cons Int Explor Mer 36:176-182

Tang D, Henyey FS, Wang Z, Williams KL and others (2008) Mid-frequency acoustic propagation in shallow water on the New Jersey shelf: intensity fluctuation. J Acoust Soc Am 124:EL91-EL96

Thompson D, Buck CD, McConnell BJ, Garrett J (1998) Foraging behavior and diet of lactating female southern sea lions in the Falkland Islands. J Zool (Lond) 246:135-146

Thomson DJ (1990) Wide-angle parabolic equation solutions to two range-dependent benchmark problems. J Acoust Soc Am 87:1514-1520

Thomson DJ, Brooke GH, DeSanto JA (1990) Numerical implementation of a modal solution to a range-dependent benchmark problem. J Acoust Soc Am 87:1521-1526

Thorne RE, Thomas GL (1990) Acoustic observations of gasbubble release by Pacific herring (Clupea harengus pallasi). Can J Fish Aquat Sci 47:1920-1928

Ticina V, Kacic I (2001) Some field observations on usefulness of searchlight sonar during bluefin tuna (Thunnus thynnus L.) fishing activities in the Adriatic Sea. Inst Oceanog Ribar Split Biljeske 85

Tolstoy I, Clay CS (1966) Ocean acoustics. McGraw-Hill, New York

Toner J, Tu Y (1998) Flocks, herds, and schools: a quantitative theory of flocking. Phys Rev E Stat Phys Plasmas Fluids Relat Interdiscip Topics 58:4828-4858

Tran A (2003) Anchovy industry data, North Carolina State University. Accessed on 26 Feb 2009. www4.ncsu. edu/ dbeggles/education/synergy/anchovy/ashanch.html

Urick RJ (1983) Principles of underwater sound, 3rd edn. McGraw-Hill, New York

Vicsek T, Czirok A, Ben-Jacob E, Cohen I, Shochet O (1995) Novel type of phase transition in a system of self-driven particles. Phys Rev Lett 75:1226-1229

Weston D (1967) Sound propagation in the presence of bladder fish. In: Albers VM (ed) Underwater acoustics, Vol 2. Plenum Press, New York, p 55-88

> Weston D, Revie J (1971) Fish echoes on a long-range sonar display. J Sound Vibrat 17:105-112

> Westwood EK (1990) Ray model solutions to the benchmark wedge problems. J Acoust Soc Am 87:1539-1545

Wilson CD, Hollowed AB, Shima M, Walline P, Stienessen S (2003) Interaction between commercial fishing and walleye pollock. Alaska Fish Res Bull 10(1):61-77

Yanez E, Silva C, Nieto K, Barbieri MA, Martinez G (2004) Using satellite technology improve Chilean purseine fish- 
Appendix A. Ocean acoustic waveguides

Remote sensing with ocean waveguide acoustics takes advantage of the fact that it is always possible to form an acoustic waveguide in the ocean by trapping sound between the ocean-atmosphere and the ocean-seabed boundaries (Bergmann 1948, Ewing \& Worzel 1948, Officer 1958, Tolstoy \& Clay 1966, Clay \& Medwin 1977, Urick 1983, Brekhovskikh \& Lysanov 1991, Frisk 1994, Jensen et al. 2000).

In continental shelf environments, most applications of long range ocean acoustics involve waveguides that are formed by interaction of sound with both of these boundaries (Officer 1958, Chapter 3; Jensen et al. 2000, Chapter 1; Clay \& Medwin 1977, Chapter 9; Urick 1983, Chapter 6; Brekhovskikh \& Lysanov 1991, Chapter 5). Even though this is often referred to as 'shallow-water acoustics' or 'littoral acoustics' the acoustic wavelength is much smaller than the ocean depth so that acoustic transmission involves many propagating modes (Fig. A1). This type of boundary-interacting, continental-shelf propagation is considered for various fish types in 'Potential ecosystem exploration' in the main paper.

Sometimes, it is possible to form acoustic waveguides in the ocean where sound does not interact with the oceanatmosphere boundary, ocean-seabed boundary or both, by appropriate experimental design involving restriction to sufficiently shallow propagation angles (Officer 1958, Tolstoy \& Clay 1966, Clay \& Medwin 1977, Urick 1983, Brekhovskikh \& Lysanov 1991, Frisk 1994, Jensen et al. 2000). In the deep ocean in mid-latitudes, for example, the combination of increasing pressure with depth and relatively warm water near the surface typically leads to a sound speed minimum at $\sim 1000 \mathrm{~m}$ depth where the acoustic field can be trapped and propagate thousands of $\mathrm{km}$ with- out interacting with either boundary. In polar environments, cold water near the surface leads to sound speed minima at, or near, the surface; so a waveguide can be formed by refraction at depth and surface reflection with sound rays that never interact with the seafloor boundary. Such sound speed structures have been exploited over the years in many remote sensing applications (Bergman 1948, Officer 1958, Clay \& Medwin 1977, Urick 1983, Brekhovskikh \& Lysanov 1991, Frisk 1994, Jensen et al. 2000). In our analysis for krill in 'Potential ecosystem exploration', we employ the latter approach, known as refract-surface-reflect (RSR; Urick 1983) propagation in an experiment designed for polar environments (see Supplement 1 at www.int-res.com/ articles/suppl/m395p137_app.pdf).

Regardless of the specific ocean waveguide, there are many standard approaches for determining the acoustic field in an ocean waveguide, including those using normal mode, wave number integration, parabolic equation and ray tracing (Jensen et al. 2000) formulations. Similarly, there are many standard models using each of these approaches, e.g. Kraken, Ocean Accoustics and Seismics Exploration Synthesis (OASES), Range-dependent Acoustic Model (RAM) and Generic Sonar Model (GSM) (Porter \& Reiss 1985, Jensen et al. 2000, Collins 1993), which have been carefully benchmarked over the years (Buckingham \& Tolstoy 1990, Collins 1990, Jensen \& Ferla 1990, Thomson 1990, Thomson et al. 1990, Stephen 1990, Westwood 1990). In 'Potential ecosystem exploration', we use the US Navy standard RAM parabolic equation model to determine transmission loss in all the continental shelf environments investigated in the present study, as described in Appendix D.

\section{a}

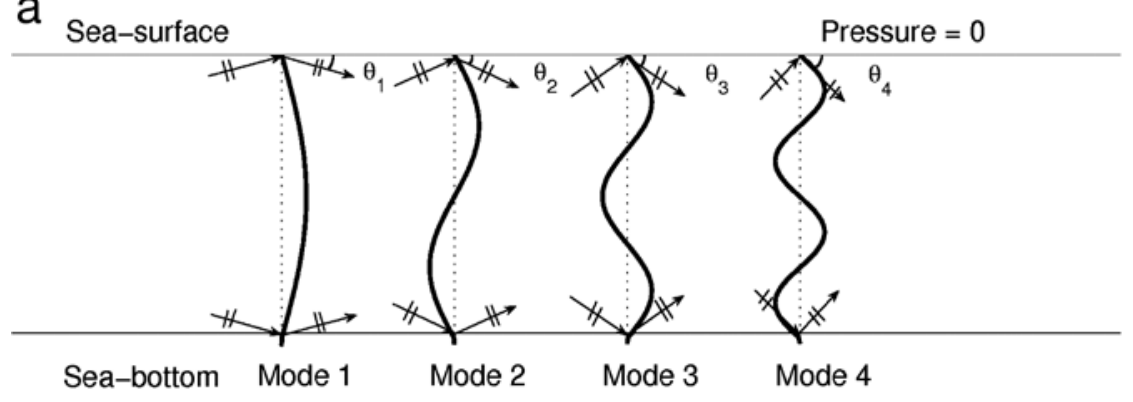

b

Sea-surface

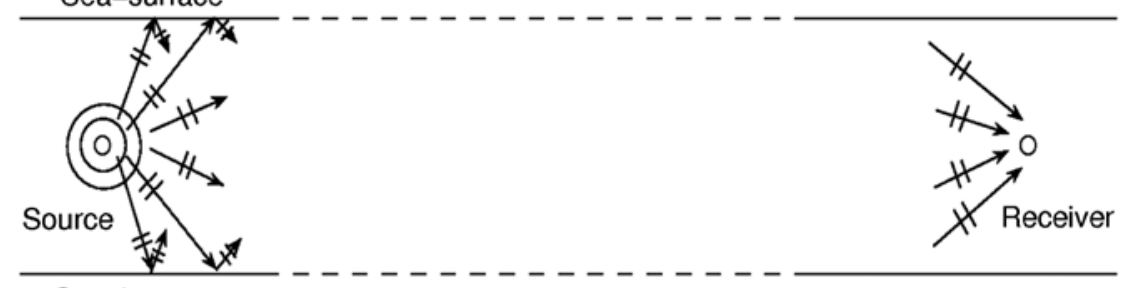

Sea-bottom

Fig. A1. Sketch illustrating boundary-interacting, long-range, modal propagation in a typical continental shelf waveguide. Spherically spreading waves from a point source are multiply reflected from the ocean-atmosphere and oceanseafloor boundaries to form vertical modes that propagate horizontally. In an iso-sound speed layer, each mode can be expressed as a vertical standing wave formed by the interference of an up and down-going plane wave of fixed horizontal grazing angle determined by the layer's boundary conditions. The sketch shows modes and equivalent plane waves for a canonical iso-sound speed continental shelf environment, known as a Pekeris waveguide

ing fleet. Gayana (Concepc) 68(2):578-585 
Appendix B. Experimental and theoretical statistics of OAWRS intensity images

In the Ocean Acoustic Waveguide Remote Sensing (OAWRS) experiments of 2003 and 2006 (Makris et al. 2006a,b, 2009a,b) acoustic returns measured by OAWRS were found to obey circular complex Gaussian random (CCGR; Goodman 1985) field fluctuations following theory (Bergmann 1948, Dyer 1970, Makris 1996, Makris et al. 2006a,b, 2009a,b) and many previous ocean acoustic experiments (Dyson et al. 1976, Lynch et al. 2003, Fredricks et al. 2005, Ratilal et al. 2005, Andrews et al. 2009b, Tang et al. 2008). The instantaneous intensity $I$ of a CCGR field follows the exponential distribution, while averaged intensity (Goodman 1985) and the log of averaged intensity (Makris 1996) follow the gamma and exponential-gamma distributions, respectively, with first and second moments that can be analytically expressed in terms of sample size $\mu$ and expected intensity $\langle I\rangle$ (Makris 1996). The standard deviation (SD) of the log of averaged intensity from a CCGR field is

$$
\sigma=\left(10 \log _{10} e\right) \sqrt{\zeta(2, \mu)}
$$

where $\zeta$ is Riemann's zeta function, and is approximately given by $\sigma=4.34 \sqrt{1 / \mu}$, for $\mu>3$ (Makris 1996) so that stationary averaging over $\mu$ independent samples asymptotically reduces the SD by $\sqrt{\mu}$, a fact that is exploited in most imaging systems which employ CCGR fields, including OAWRS, to obtain low variance images.

In the OAWRS 2003 experiment, the empirically determined SD of the log of averaged intensity from OAWRS
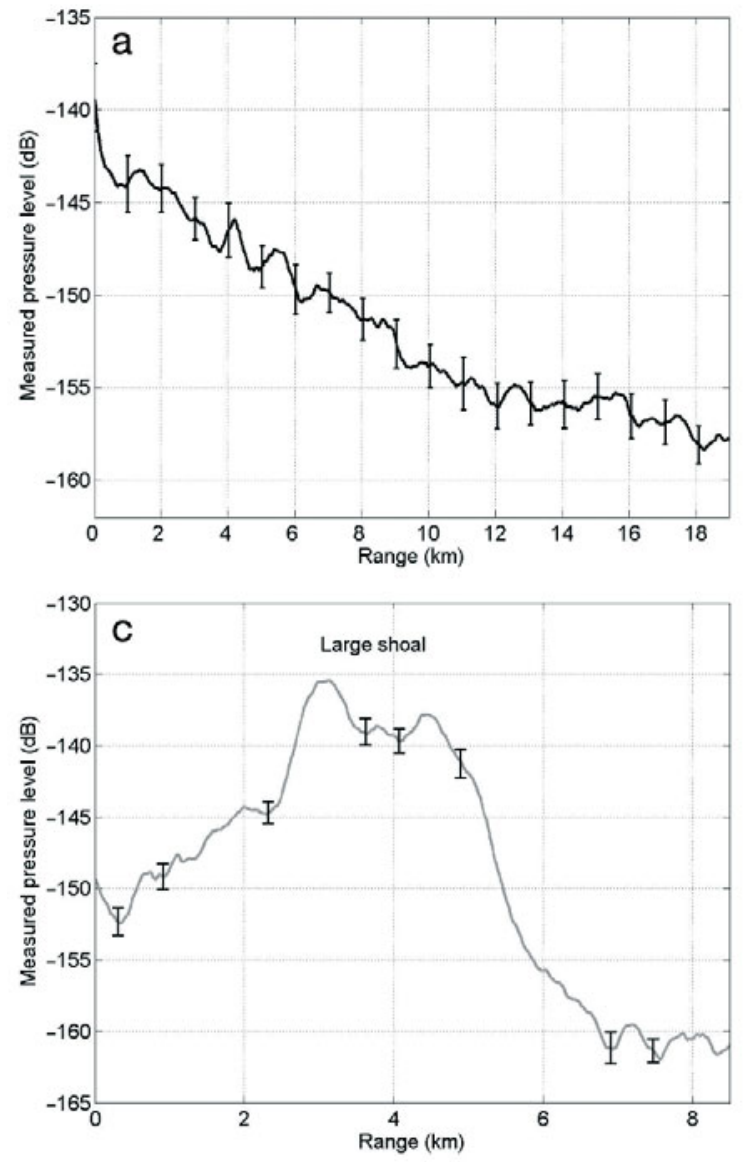

imagery is on the order of $1 \mathrm{~dB}$ at a given OAWRS pixel. For example, a $\sim 1.3 \mathrm{~dB}$ SD is measured for the log of averaged intensity at any pixel, as shown in Fig. B1a where no large fish groups are present and the scattered returns leading to the observed intensity measurements are consistent with returns from the seafloor. The same $\sim 1.3 \mathrm{~dB}$ SD is also measured for OAWRS imaging of a large fish shoal (Fig. B1b,c). In both cases, the low SD are the result of 10 sample ( 5 temporal, 2 range) averaging, and closely follow the $1.4 \mathrm{~dB}$ theoretically expected from Eq. (B1), as has been noted by Makris et al. (2006a,b). The $\sim 20 \mathrm{~dB}$ contrast between fish shoals and background seafloor scattering (Fig. B1) is much larger than the $\sim 1.3 \mathrm{~dB} \mathrm{SD}$, which is low enough to make details in shoal morphology discernable. Log-transformed intensity is used to present OAWRS imagery data since pattern recognition in intensity images formed from CCGR field data is optimized by matching in the log domain where noise is signal-independent and the variance is stabilized (Makris 1995) by homomorphic transformation. Similar SD for the log of measured intensity in the OAWRS 2006 experiment were obtained by stationary averaging (Makris et al. 2009b).

In the OAWRS 2003 and 2006 experiments, averaged intensity returns from the seafloor exhibited a trend of smooth decay with range (Fig. B1, Fig. S5 in Makris et al. 2009b) following theoretical expectations for uniformly distributed waveguide scatterers (Bucker 1970, Ellis 1995,

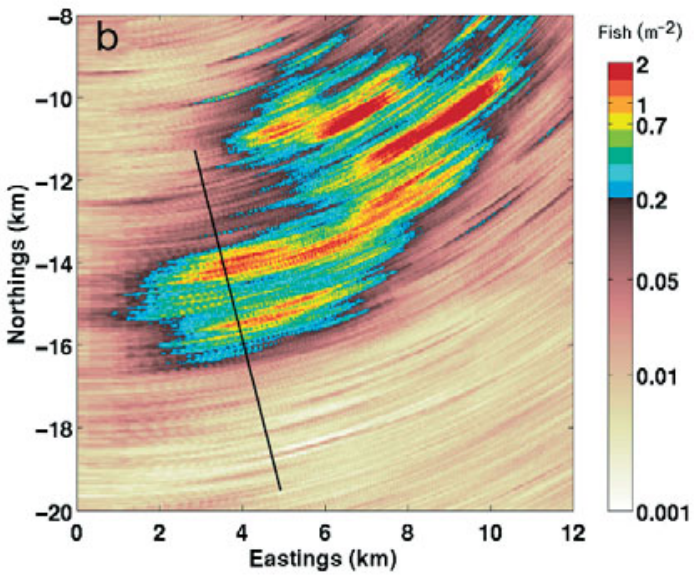

Fig. B1. (a) Averaged intensity measured by OAWRS in the absence of prominent fish shoals, normalized to unit source power, from the OAWRS 2003 survey shows a trend of smooth decay with range. Returns are consistent with scattering from the seafloor. Error bars = experimentally determined SD of $\sim 1.3 \mathrm{~dB}$ for the standard 10 sample (5-ping and 2-range-cell) intensity average employed in OAWRS 2003. (b) Instantaneous OAWRS image of fish population density showing a large fish shoal (10:25 h Eastern daylight time [EDT]; May 14, 2003). Solid black line = transect through the shoal along which averaged intensity is shown in (a). This image is typical of thousands collected during the 2003 OAWRS survey (Makris 2003). (c) Averaged intensity measured by OAWRS along the transect through a large fish shoal in (b), with experimentally determined SD of $\sim 1.3 \mathrm{~dB}$ 
Appendix B (continued)

Makris \& Ratilal 2001) and many measurements of seafloor reverberation and transmission in the ocean (Bucker 1970, Makris et al. 1995, Smith \& Cushman 1997, Harding et al. 1998, Hines et al. 1998, Preston 2000, Ratilal et al. 2005, Andrews et al. 2009b, Makris et al. 2009b). The smooth trend is expected because the many independent modal contributions from random propagation and scattering that lead to CCGR field statistics by the central limit theorem (CLT) also lead to a lack of coherent modal interference structure (Bucker 1970, Ellis 1995, Makris \& Ratilal 2001, Chen et al. 2005, Ratilal \& Makris 2005, Makris et al. 2006b, Chen et al. 2008). Randomization of the acoustic field arises from both fluctuations in the water column due to diverse phenomena such as internal waves, eddies, turbulence, boundary roughness at the sea surface and seafloor, as well as fluctuations in the properties of scatterers such as position, aspect and composition.

The instantaneous intensity of conventional fish-finding sonar (CFFS) returns from fish vary significantly as a function of fish aspect and also follow CCGR statistics (Dahl \& Mathisen 1983) as a consequence of the CLT (Clay \& Medwin 1977). It has also been noted (Makris 1996) that as a consequence of the CLT, the same CCGR field, averaged intensity and log averaged intensity statistics are found in CFFS scattering from fish and in ocean-acoustic waveguide transmission scintillation, where stationary averaging is typically needed in all cases to produce low variance images. The $5.6 \mathrm{~dB}$ instantaneous intensity $\mathrm{SD}$, for example, is often too high for many imaging applications and is typically reduced by stationary averaging (Makris 1996).

Appendix C. Expected intensity in OAWRS imaging of fish groups

The expected square magnitude of the field, $\left\langle\left|\phi_{\mathrm{S}}\left(\rho_{\mathrm{C}}\right)\right|^{2}\right\rangle$, proportional to instantaneous intensity, scattered from $N$ independent and identically distributed fish with random position, orientation and scattering properties within the OAWRS resolution footprint of area $A\left(\rho_{\mathrm{C}}\right)$, centered at horizontal location $\rho_{\mathrm{C}}$ can be expressed as (Andrews et al. 2009a)

$$
10 \log _{10}\left\langle\left|\phi_{\mathrm{S}}\left(\rho_{\mathrm{C}}\right)\right|^{2}\right\rangle=\mathrm{SL}+\mathrm{TLA}\left(\rho_{\mathrm{C}} z_{0}, H\right)+10 \log _{10}\left\langle\left|\frac{S(f)}{k}\right|^{2}\right\rangle+10 \log _{10}\left\langle n_{a}\right\rangle
$$

where SL is the source level normalization, TLA is a transmission loss area term describing the expected second moment of depth averaged propagation to and from the fish layer integrated over the resolution footprint of the OAWRS system, $S(f)$ is the random scatter function of a fish in the group, $k$ is the acoustic wavenumber, and $\left\langle n_{\mathrm{a}}\right\rangle=N / A\left(\rho_{\mathrm{C}}\right)$ is the expected areal fish density within the spatially varying resolution footprint.

The third term on the right hand side of Eq. (C1) is defined as the target strength (TS) corresponding to the expected scattering cross section of a fish in the group. The TLA term, a function of center depth $z_{0}$ and thickness of the fish layer $H$, can be expressed as

$$
\operatorname{TLA}\left(\rho_{\mathrm{C}}, z_{0}, H\right)=10 \log _{10} \chi\left(\rho_{\mathrm{C}}, z_{0}, H\right)
$$

$\chi\left(\rho_{\mathrm{C}}, z_{0}, H\right)=$

$$
\int_{A\left(\rho_{\mathrm{C}}\right)} A\left(\rho_{\mathrm{C}}\right) \int_{z_{\mathrm{S}}=z_{0}-H / 2}^{z_{\mathrm{S}}=z_{0}+H / 2} \iint_{C\left(r_{W}\right), d\left(r_{W}\right)}(4 \pi)^{4}\left|G\left(\boldsymbol{r} \mid \rho_{\mathrm{S}}, z_{\mathrm{S}} ; f, C\left(\boldsymbol{r}_{W}\right), d\left(\boldsymbol{r}_{W}\right)\right) G\left(\rho_{\mathrm{S}}, z_{\mathrm{S}} \mid \boldsymbol{r}_{0} ; f, C\left(\boldsymbol{r}_{W}\right), d\left(\boldsymbol{r}_{W}\right)\right)\right|^{2} P\left(C\left(\boldsymbol{r}_{W}\right), d\left(\boldsymbol{r}_{W}\right)\right) P\left(\rho_{\mathrm{S}}, z_{\mathrm{S}}\right) \mathrm{d} z_{\mathrm{S}} \mathrm{d}^{2} \rho_{\mathrm{S}} \mathrm{d} C\left(\boldsymbol{r}_{W}\right) \mathrm{d} d\left(\boldsymbol{r}_{W}\right)
$$

where $G\left(r \mid \rho_{\mathrm{S}}, z_{\mathrm{S}} ;, C\left(\boldsymbol{r}_{W}\right), d\left(\boldsymbol{r}_{W}\right)\right)$ and $G\left(\rho_{\mathrm{S}}, z_{\mathrm{S}} \mid \boldsymbol{r}_{0} f, c\left(\boldsymbol{r}_{W}\right), d\left(\boldsymbol{r}_{W}\right)\right)$ are Green functions describing random waveguide propagation to and from the fish, $P\left(c\left(\boldsymbol{r}_{W}\right), d\left(\boldsymbol{r}_{W}\right)\right)$ is the joint probability distribution of sound speed $c$ and seawater density $d$ in the water column at any point $\boldsymbol{r}_{W}$ in the propagation path and $P\left(\rho_{\mathrm{S}}, Z_{\mathrm{S}}\right)$ is the probability of finding a fish at $\rho_{\mathrm{S}} z_{\mathrm{S}}$. For a uniform distribution of fish within the OAWRS resolution footprint $P\left(\rho_{S}, z_{\mathrm{S}}\right)=\frac{1}{H} \frac{1}{A\left(\rho_{\mathrm{C}}\right)}$, so that

$$
\chi\left(\rho_{\mathrm{C}}, z_{0}, H\right)=\int_{A\left(\rho_{\mathrm{C}}\right)} \frac{1}{H} \int_{z_{\mathrm{S}}=z_{0}-H / 2}^{z_{\mathrm{S}}=z_{0}+H / 2}(4 \pi)^{4}\left\langle\left|G\left(\boldsymbol{r} \mid \rho_{\mathrm{S}}, z_{\mathrm{S}} ; f, C\left(\boldsymbol{r}_{W}\right), d\left(\boldsymbol{r}_{W}\right)\right) G\left(\rho_{\mathrm{S}}, z_{\mathrm{S}} \mid \boldsymbol{r}_{0} ; f, C\left(\boldsymbol{r}_{W}\right), d\left(\boldsymbol{r}_{W}\right)\right)\right|^{2} \mid \rho_{\mathrm{S}}, z_{\mathrm{S}}\right\rangle \mathrm{d} z_{\mathrm{S}} \mathrm{d}^{2} \rho_{\mathrm{S}}
$$

where the conditional expectation is over the water column sound speed and density random variables.

Appendix D. Transmission loss over the OAWRS resolution footprint

The transmission loss area (TLA) term in Eq. (C1) is computed using the US Navy standard range-dependent acoustic model (RAM) (Collins 1993) in conjunction with measured oceanographic data including sound speed of the water column and sediment, sediment density and attenuation, and bathymetry.

The TLA computed for all the environments considered in this paper are displayed in Fig. D1a,b and show the trend of smooth decay with range expected from theory (Bucker 1970, Ellis 1995, Makris \& Ratilal 2001, Chen et al. 2005), measured seafloor reverberation (Fig. B1a, Galinde et al.
2008) and past experiments (Lynch et al. 2003, Fredricks et al. 2005, Ratilal et al. 2005, Tang et al. 2008). They also exhibit low SDs of $\sim 1$ to $1.5 \mathrm{~dB}$ over expected fish shoal depths (Table 1).

To determine TLA, the Green functions in Eq. (C3) are computed with the RAM parabolic equation model (Collins 1993, Jensen et al. 2000) for an ocean-acoustic waveguide. The conditional expectation value in Eq. (C3) is determined by averaging 100 Monte-Carlo realizations, where the Green functions are computed along the entire propagation path in range and depth for each realization. 
Appendix D (continued)

Each Monte-Carlo realization itself employs a different sound speed depth profile every $500 \mathrm{~m}$ (Chen et al. 2005, Andrews et al. 2009b) along the propagation path. Measured sound speed profiles from the OAWRS 2003 experiment (Fig. D1c) are used to generate TLA in Fig. D1a, and from the Argo Database (2009) (Fig. D1d) to generate TLA in Fig. D1(b). The SD of TLA over a depth layer $H_{\text {, is }}$ defined as
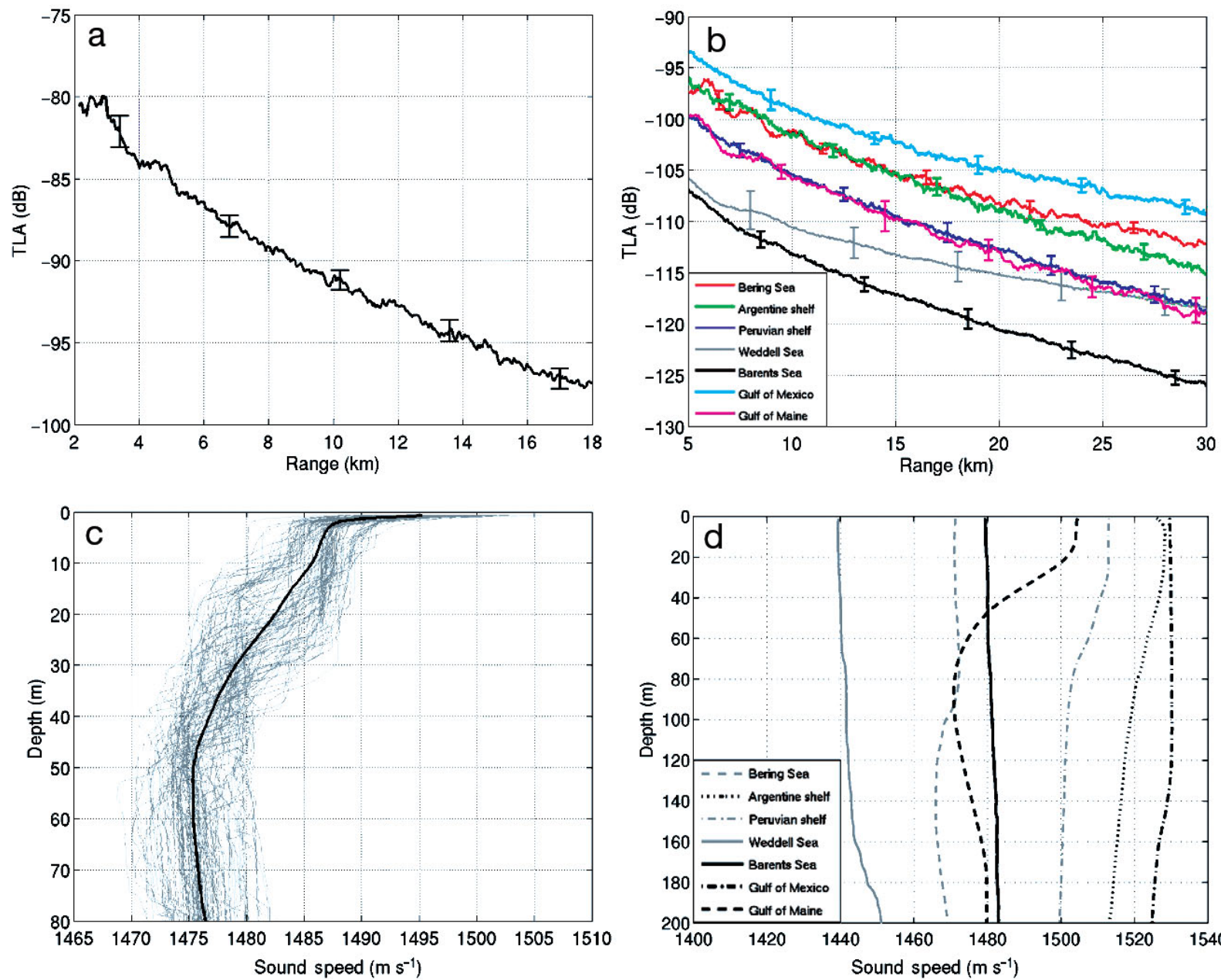

Fig. D1. (a) Expected 2-way transmission loss area term (TLA) computed by Monte-Carlo simulation for the OAWRS 2003 experimental environment (continental shelf south of Long Island, NY), for the $H=30 \mathrm{~m}$ and $z_{0}=65 \mathrm{~m}$ where fish shoals were observed by CFFS. Error bars show the TLA SD $(\sigma)$ of 1 to $1.5 \mathrm{~dB}$ over the depths of this fish shoal layer. (b) Expected 2-way TLA for the environments considered in 'Potential ecosystem exploration' in the main paper. For each environment, the mean TLA is computed by averaging over the expected fish shoal depth (Table 1). Error bars indicate the SD in TLA over these depths. The water depths in the different environments are (1) $150 \mathrm{~m}$ for Bering Sea, Gulf of Mexico, Peru, Barents Sea, (2) $180 \mathrm{~m}$ for Gulf of Maine, and (3) $200 \mathrm{~m}$ for Argentina, Antarctica. (c) Sound speed profiles measured during the OAWRS 2003 survey in the continental shelf south of Long Island, NY, and used to compute TLA in (a). (d) Measured sound speed profiles for various continental shelf environments (Argo Database 2009) used to compute TLA in (b). The environments span the canonical cases of upward refracting (Antarctic), well-mixed (Gulf of Mexico), downward refracting (Peru), and a deep water sound speed minimum (Gulf of Maine) 
Appendix E. Empirical estimation of target strength and areal population density from OAWRS data

The target strength (TS) at OAWRS frequencies, TS OAWRS $_{1}$ is estimated using (1) OAWRS measurements of averaged intensity, (2) modeled TLA, and (3) simultaneous CFFS measurements of number density. Stationary averaging is then employed over hundreds of OAWRS and CFFS samples to obtain a low variance $\mathrm{TS}_{\text {OAWRS }}$ estimate, using OAWRS fish population density maps such as those shown in Figs. 2 \& B1b.

The maximum likelihood estimate (MLE)

$$
\begin{gathered}
\widehat{\operatorname{TS}}_{\text {OAWRS }}\left(\rho_{\mathrm{S}}, f\right)=10 \log _{10}\left|\frac{\widehat{S(f)}}{k}\right|^{2}=10 \log _{10}\left|\phi_{\mathrm{S}} \widehat{\left(\rho_{\mathrm{S}}, f\right)}\right|^{2}- \\
10 \log _{10} \hat{\chi}\left(\rho_{\mathrm{c}}, z_{0}, H, f\right)-10 \log _{10} \widehat{n_{\mathrm{a}}}\left(\rho_{\mathrm{c}}\right)-\mathrm{SL}
\end{gathered}
$$

is obtained from invariance of the MLE (Kay 1993) as prescribed by evaluation of parameters at their corresponding MLEs in Eq. (C1). While the first 2 terms on the right hand side of Eq. (E1) are estimated from OAWRS measurements of averaged intensity (Appendix B) and modeled TLA (Appendix D), respectively, the areal fish number density $n_{a}$ is estimated from simultaneous CFFS measurements as

$$
10 \log _{10} \widehat{n_{a}}\left(\rho_{\mathrm{c}}\right)=\widehat{\mathrm{SS}}_{\mathrm{C}}\left(\rho_{\mathrm{c}}\right)-\widehat{\mathrm{TS}}_{\mathrm{C}}
$$

where $\mathrm{SS}_{\mathrm{C}}$ is CFFS-measured scattering strength and $\mathrm{TS}_{\mathrm{C}}$ is the target strength of an individual fish at the CFFS operating frequency.

Table E1. SD of different terms on the right hand side of Eqs. E1 and E2 before and after stationary averaging over OAWRS pixels $(n=181)$. Note that SD of the CFFS target strength estimate $\widehat{T S}_{c}$ is not affected by averaging over OAWRS data

\begin{tabular}{|lcc|}
\hline Terms in Eqs. (E1) \& (E2) & $\begin{array}{c}\text { SD per } \\
\text { OAWRS pixel } \\
(\mathrm{dB})\end{array}$ & $\begin{array}{c}\text { SD after } \\
\text { stationary } \\
\text { averaging } \\
(\mathrm{dB})\end{array}$ \\
\hline $10 \log _{10}\left|\phi_{\mathrm{s}} \widehat{\left(\rho_{\mathrm{C}}, f\right)}\right|^{2}$ & 1.3 & 0.09 \\
$10 \log _{10} \hat{\chi}\left(\rho_{\mathrm{C}}, z_{0}, H, f\right)$ & 0.5 to 1 & 0.07 \\
$\widehat{\mathrm{SS}}_{\mathrm{c}}\left(\rho_{\mathrm{C}}\right)$ & 1.5 & 0.11 \\
$\widehat{\mathrm{TS}}_{\mathrm{C}}$ & 0.65 & 0.65 \\
$\widehat{\mathrm{TS}}_{\mathrm{OAWRS}}$ & 2.3 & 0.67 \\
\hline
\end{tabular}

We now explain how the SD of the fish target strength estimate at $415 \mathrm{~Hz}$ from OAWRS 2003 data shown in Fig. 5 in the main paper was determined and how it is consistent with theory and other measurements. At a given OAWRS 2003 pixel, the variance (i.e. $\mathrm{SD}^{2}$ ) of $\widehat{\mathrm{TS}}_{\text {OAWRS }}$ is the sum of the variances of each term on the right hand side of Eq. (E1), given their independence. For the first 2 terms, $10 \log _{10}\left|\phi_{s}\left(\rho_{\mathrm{C}} f\right)\right|^{2}$ and $10 \log _{10} \hat{\chi}\left(\rho_{\mathrm{C}}, z_{0}, H, f\right)$, the SD are $1.3 \mathrm{~dB}$ (Appendix B) and $1 \mathrm{~dB}$ (Appendix D), respectively. The variance of the third term, $10 \log _{10} \widehat{n_{a}}\left(\rho_{C}\right)$, is the sum of the variances of $\widehat{\mathrm{SS}}_{\mathrm{c}}$ and $\widehat{\mathrm{TS}}_{\mathrm{c}}$, given the independence of the terms in Eq. (E2). The SD of $\widehat{\mathrm{SS}}_{\mathrm{c}}$ and $\widehat{\mathrm{TS}}_{\mathrm{c}}$ are $1.5 \mathrm{~dB}$ and $0.65 \mathrm{~dB}$ per OAWRS pixel, respectively, from CFFS measurements made during the OAWRS 2003 experiment. The resulting $\mathrm{SD}$ of $\mathrm{TS}_{\text {OAWRS, }}$ per OAWRS pixel, is then $2.3 \mathrm{~dB}$.

Estimates of TS $\mathrm{S}_{\mathrm{OAWR}}$ based on many independent OAWRS pixels within regions of statistically stationary fish populations are then averaged to reduce the SD. During the OAWRS 2003 experiment, both OAWRS and CFFS co-registered many fish shoals with statistically stationary populations, such as the one shown in Fig. B1. The SD of all the terms on the right hand side of Eqs. (E1) \& (E2) after stationary averaging over 181 OAWRS samples, obtained within such stationary populations, are summarized in Table E1. Note that the SD of $\widehat{\mathrm{TS}}_{\mathrm{c}}$ cannot be reduced by averaging OAWRS data because it is assumed not to vary across OAWRS samples. After stationary averaging, the theoretical and empirical SD of $0.67 \mathrm{~dB}$ (Table E1) for TS $\widehat{T}_{\text {OAWRS }}$ agrees well with the empirically determined value of $0.7 \mathrm{~dB}$ shown in Table E2 \& Fig. 5.

To estimate OAWRS areal number densities over the wide areas shown in Figs. 3 in the main paper \& B1b, Eq. (C1) is again employed by now grouping together all terms except $10 \log _{10} n_{\mathrm{a}}\left(\rho_{\mathrm{C}}\right)$, and using the empirically estimated $\mathrm{TS}_{\text {OAWRS }}$. Extrapolating $\widehat{\mathrm{TS}}_{\mathrm{OAWRS}}$ in an OAWRS image to spatial locations where there are no CFFS measurements is valid when the fish obey stationary random processes in their spatial distribution and scattering properties.

The variance of the OAWRS areal number density, at any given OAWRS pixel, is the sum of the variances of $10 \log _{10}\left|\phi_{s} \widehat{\left(\rho_{C}, f\right)}\right|^{2}, 10 \log _{10} \hat{\chi}\left(\rho_{C}, z_{0}, H, f\right)$ and TS $\widehat{T O A w R S}_{\text {. Using }}$ the SD in Tables E1 \& E2, OAWRS 2003 estimates of number density then have a SD of $1.5 \mathrm{~dB}$ for statistically stationary fish populations.

Table E2. Empirically estimated target strength (TS) at $415 \mathrm{~Hz}$ for OAWRS 2003 experiment. Six transects through statistically

\begin{tabular}{|c|c|c|c|c|c|}
\hline $\begin{array}{l}\text { Day } \\
\text { (May 2003) }\end{array}$ & $\begin{array}{l}\text { Time } \\
\text { (EDT) }\end{array}$ & $\begin{array}{l}\text { Transect } \\
\text { length through } \\
\text { shoal (m) }\end{array}$ & $\begin{array}{l}\text { Average } n_{V} \\
\text { (CFFS), } \\
\text { fish } \mathrm{m}^{-3}\end{array}$ & $\begin{array}{c}\text { No. of } \\
\text { independent } \\
\text { samples (n) }\end{array}$ & $\begin{array}{c}\text { Least squares } \\
\text { TS }_{\text {OAWrS }} \\
\text { (dB re } 1 \mathrm{~m}^{2} \text { at } 415 \mathrm{~Hz} \text { ) }\end{array}$ \\
\hline 14 & $12: 17$ & 3000 & 0.04 & 85 & -39.7 \\
\hline 14 & $14: 03$ & 3500 & 0.03 & 59 & -40.1 \\
\hline 15 & $10: 08$ & 210 & 0.02 & 12 & -40.3 \\
\hline 15 & $11: 19$ & 105 & 0.02 & 6 & -40.3 \\
\hline 15 & $12: 20$ & 87 & 0.02 & 2 & -39.8 \\
\hline \multirow[t]{3}{*}{15} & $13: 19$ & 306 & 0.02 & 17 & -39.8 \\
\hline & & & & Mean $\mathrm{TS}_{\text {OAWRS }}$ & -40.0 \\
\hline & & & & SD TS OAWRS $_{\text {OAW }}$ & 0.7 \\
\hline
\end{tabular}
stationary fish populations co-registered by OAWRS and CFFS are used to compute the least squares estimate (effectively same as MLE for the given data) and standard deviation of $\mathrm{TS}_{\mathrm{OAWRS}} \cdot \mathrm{n}_{\mathrm{V}}=$ number density. EDT = Eastern Daylight Time 
Appendix F. Signal to noise ratio in OAWRS intensity images

The signal to noise ratio (SNR) in OAWRS images is the ratio of the expected scattered intensity from fish to that from the seafloor

$$
\mathrm{SNR}=10 \log _{10} \frac{\left\langle\left|\phi_{\mathrm{S}}\right|_{\text {fish }}^{2}\right\rangle}{\left\langle\left|\phi_{\mathrm{S}}\right|^{2}{ }_{\text {bottom }}\right\rangle}
$$

Expressions for the second moment of the scattered field from fish groups, $\left\langle\left|\phi_{\mathrm{s}}\right|^{2}\right\rangle_{\text {fish }}$, proportional to the expected scattered intensity, appear in Appendix C.

The second moment of the scattered field from the seabottom, $\left\langle\left|\phi_{\mathrm{s}}\right|^{2}\right\rangle_{\text {bottom, }}$, depends on seafloor scattering properties. Seafloor scattering has been studied extensively since World War II, and empirical models have been used to describe various field measurements (Urick 1983). For most seabottom types, including sand, silt and rocky bottoms, little or no frequency dependence has been measured in seafloor scattering strength over the OAWRS frequencies considered here (Urick 1983). Seafloor scattering properties measured recently (Galinde et al. 2008) are used for all continental shelves considered here for a typical sandy bottom. The seafloor returns for all the environments discussed in 'Potential ecosystem exploration' in the main paper are computed by using the scattering model developed in Galinde et al. (2008). 